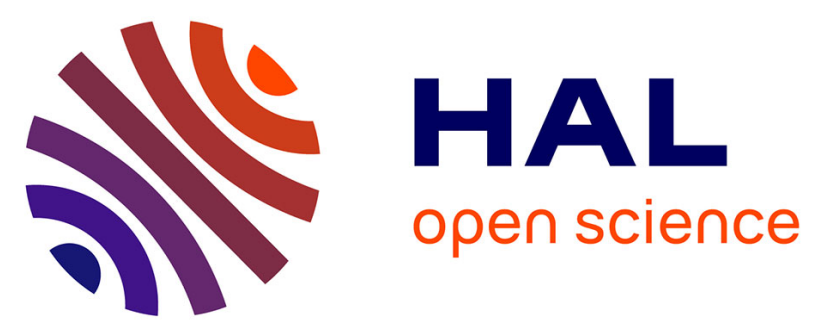

\title{
Complete genome sequence of Bacillus velezensis QST713: A biocontrol agent that protects Agaricus bisporus crops against the green mould disease
}

Caroline Pandin, Dominique Le Coq, Julien Deschamps, Régis Védie, Thierry Rousseau, Stéphane Aymerich, Romain Briandet

\section{To cite this version:}

Caroline Pandin, Dominique Le Coq, Julien Deschamps, Régis Védie, Thierry Rousseau, et al.. Complete genome sequence of Bacillus velezensis QST713: A biocontrol agent that protects Agaricus bisporus crops against the green mould disease. Journal of Biotechnology, 2018, 278, pp.10-19. 10.1016/j.jbiotec.2018.04.014 . hal-02353465

\section{HAL Id: hal-02353465 \\ https://hal.science/hal-02353465}

Submitted on 2 Mar 2022

HAL is a multi-disciplinary open access archive for the deposit and dissemination of scientific research documents, whether they are published or not. The documents may come from teaching and research institutions in France or abroad, or from public or private research centers.
L'archive ouverte pluridisciplinaire HAL, est destinée au dépôt et à la diffusion de documents scientifiques de niveau recherche, publiés ou non, émanant des établissements d'enseignement et de recherche français ou étrangers, des laboratoires publics ou privés. 
Manuscript Number: JBIOTEC-D-18-00237

Title: Complete genome sequence of Bacillus velezensis QST713: a biocontrol agent that protects Agaricus bisporus crops against the green mould disease.

Article Type: Short Genome Communications

Section/Category: Short Genome Communications

Keywords: Bacillus velezensis, Biofilm, Genome, Biocontrol, Secondary metabolites

Corresponding Author: Miss Caroline Pandin,

Corresponding Author's Institution: INRA

First Author: Caroline Pandin

Order of Authors: Caroline Pandin; Dominique Le Coq; Julien Deschamps; Régis Védie; Thierry Rousseau; Stéphane Aymerich; Romain Briandet

Abstract: Bacillus subtilis QST713 is extensively used as a biological control agent in agricultural fields including in the button mushroom culture, Agaricus bisporus. This last use exploits its inhibitory activity against microbial pathogens such as Trichoderma aggressivum $f$. europaeum, the main button mushroom green mould competitor. Here, we report the complete genome sequence of the QST713 biocontrol strain with a genome size of 4233757 bp, 4263 predicted genes and an average GC content of 45.9\%. Based on phylogenomic analyses, the QST713 strain is finally designated as Bacillus velezensis. Genomic analyses revealed two clusters encoding potential new antimicrobials with NRPS and TransATPKS synthetase. B. velezensis QST713 genome also harbours several genes previously described as being involved in surface colonization and biofilm formation. This strain shows a strong ability to form in vitro spatially organized biofilm and to antagonize T. aggressivum. The availability of this genome sequence could bring new elements to understand the interactions with micro or/and macroorganisms in crops.

Suggested Reviewers: Ken-Ichi Yoshida

PhD, Department of Science, Technology and Innovation, Kobe University kenyoshi@kobe-u.ac.jp

published genomes from the same species recently

Ming Xiao

PhD, Biology Department, College of Life and Environment Sciences, Shanghai Normal University

xiaom88eshnu.edu.cn

published genomes from the same species recently

Zaigui Wang

PhD, College of Life Science, Anhui Agricultural University wangzaigui2013@163. com 
published very recently a review about B. velezensis species

Ming Sun

PhD, State Key Laboratory of Agricultural Microbiology, College of Life Science and $T$, Huazhong Agricultural University

m98sun@mail.hzau.edu.cn

recently published a genome from the same species

Conor Francis McGee

PhD, Department of Agriculture, Food and the Marine, Backweston Campus conorfmcgeelgmail.com

specialist in microbial ecology of the Agaricus bisporus mushroom cropping process

Lin Shen

PhD, College of Food Science and Nutritional Engineering, China

Agricultural University

shen5000@cau.edu.cn

Specialist of Agaricus bisporus culture process 
Jouy-en-Josas, the $22^{\text {th }}$ of February 2018

\section{Dear Editor,}

Please find attached the manuscript entitled "Complete genome sequence of Bacillus velezensis QST713: a biocontrol agent that protects Agaricus bisporus crops against the green mould disease." to be submitted for publication in "Journal of Biotechnology".

The main objective of this paper is to publish the complete genome sequence of the Bacillus velezensis QST713 strain, and to show its particularities compared to other species of the Bacillus subtilis species complex. This strain is hugely used as biological control agent in the world and for almost ten years in the field of the button mushroom Agaricus bisporus in France, but it is poorly documented. In this paper, we described the genome sequence of the QST713 strain and we show a strong capability to form biofilm and to produce two potential new antimicrobials compared to other Bacillus species. Furthermore, we show its ability to antagonize the pathogen of A. bisporus and to restore a great yield of A. bisporus through a biocontrol assay performed at the technical mushroom center in France. The publication of this genome sequence could permit a better understanding of the bioprotection mechanisms involved in interactions with macro- and microorganisms in agriculture. The biofilm mode of life and its specificities only start to be taken in consideration for the biotechnological use of beneficial organisms in agriculture. Invoking biofilm-associated mechanisms in the beneficial effects of biocontrol agents opens doors for sustainable biofilm applications as an alternative to chemical pollutants.

All authors agreed to submit this work and the manuscript has not been submitted to another journal. We believe that the reading of this paper should be of interest for readers of Journal of Biotechnology.

Best regards,

\section{Caroline Pandin}

Micalis Institute,

INRA, AgroParisTech, Université Paris-Saclay,

Domaine de Vilvert

78350 Jouy-en-Josas

FRANCE

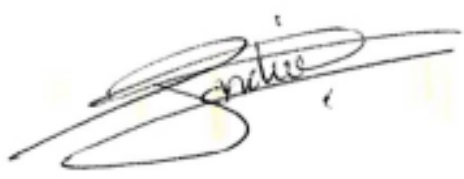




\section{Highlights}

* Bacillus velezensis QST713 is hugely used as biocontrol agent in the world and strongly protects Agaricus bisporus crops against Trichoderma aggressivum f. europaeum in France.

* The complete genome of this commercial biofungicide was sequenced and described.

* It encodes at least 15 secondary metabolite gene clusters including two potential new antimicrobials.

* It forms robust and highly complex 3D structured biofilm.

* The availability of the genome data also provides information for further exploration and understanding of biocontrol mechanisms during interactions between microorganisms and micro-/macroorganisms in crops 
1 Complete genome sequence of Bacillus velezensis QST713: a biocontrol agent that

2 protects Agaricus bisporus crops against the green mould disease.

3

4 Caroline Pandin ${ }^{1}$, Dominique Le $\mathrm{Coq}^{1,2}$, Julien Deschamps ${ }^{1}$, Régis Védie $^{3}$, Thierry $5 \quad$ Rousseau $^{3}$, Stéphane Aymerich ${ }^{1}$, Romain Briandet $^{1}$

6

$7{ }^{1}$ Micalis Institute, INRA, AgroParisTech, Université Paris-Saclay, 78350 Jouy-en-Josas, 8 France.

$9 \quad{ }^{2}$ Micalis Institute, INRA, AgroParisTech, CNRS, Université Paris-Saclay, 78350 Jouy-en10 Josas, France.

$11{ }^{3}$ Centre Technique du Champignon, 49400 Distré, France.

12

13 Corresponding author; E-Mail: romain.briandet@inra.fr; caroline.pandin@inra.fr; Tel: $14+33.1 .74 .07 .16 .98$.

Abstract

18 Bacillus subtilis QST713 is extensively used as a biological control agent in agricultural fields 19 including in the button mushroom culture, Agaricus bisporus. This last use exploits its 20 inhibitory activity against microbial pathogens such as Trichoderma aggressivum $\mathrm{f}$. 21 europaeum, the main button mushroom green mould competitor. Here, we report the complete 22 genome sequence of the QST713 biocontrol strain with a genome size of 4233757 bp, 4263 23 predicted genes and an average GC content of $45.9 \%$. Based on phylogenomic analyses, the 24 QST713 strain is finally designated as Bacillus velezensis. Genomic analyses revealed two 25 clusters encoding potential new antimicrobials with NRPS and TransATPKS synthetase. $B$. 
velezensis QST713 genome also harbours several genes previously described as being involved in surface colonization and biofilm formation. This strain shows a strong ability to form in vitro spatially organized biofilm and to antagonize $T$. aggressivum. The availability of this genome sequence could bring new elements to understand the interactions with micro or/and macroorganisms in crops.

Keywords : Bacillus velezensis, Biofilm, Genome, Biocontrol, Secondary metabolites.

\section{(1)}

\section{Introduction}

Bacillus spp. are ubiquitous bacteria found in soils that are widely used as biocontrol agents because of their ability to antagonize crops pathogens and the possibility to develop stable spore-based commercial products (Borriss 2015). The described mechanisms associated with their biocontrol effect include specific antagonism, spatial and nutritional competition, antimicrobial production, stimulation of plant growth, and induction of plant resistance (Pandin et al. 2017). Bacilli biocontrol agents are able to secrete a wide range of secondary metabolites that can display antibacterial, antifungal, or both properties (Stein 2005; Ongena \& Jacques 2008; Chen et al. 2009; Zhao \& Kuipers 2016). Another ability that should be emphasized in the field of biocontrol is the formation of spatially organized biofilms, the most prevalent microorganisms mode of life in environment that allow a better colonization and persistence of microorganisms (Costerton et al. 1978, 1999; Morris et al. 2003; Epstein et al. 2011; Xu et al. 2014; Zeriouh et al. 2014; Abd el Daim et al. 2015; Pandin et al. 2017). For almost ten years, Bacillus velezensis QST713 is used for the bioprotection of the button mushroom cultures in France against Trichoderma aggressivum f. europaeum. This fungal pathogen hinders the development of Agaricus bisporus by invading its culture substrate, the compost (Mamoun et al. 2000; Samuels et al. 2002; Largeteau \& Savoie 2010). However, 
published reports on this specific strain are very scarce and its genome sequence is unknown from databanks (Joshi and McSpadden Gardener 2006; Patel et al. 2011; Lahlali et al. 2013; Cawoy et al. 2015; Punja et al. 2016). In this study, the genome sequence of the commercial strain QST713 was determined, described and compared to other Bacillus strains. Furthermore, phenotypic tests and biocontrol assay were carried out to emphasis abilities of this biocontrol strain.

\section{Genomic structure and comparative genome analysis of Bacillus velezensis QST713} with Bacillus strains

Genomic DNA was extracted from B. velezensis QST713 cultivated at $37^{\circ} \mathrm{C}$ in LuriaBertani medium (LB, Sigma, France) using the GenElute ${ }^{\mathrm{TM}}$ Bacterial Genomic DNA extraction Kit (Sigma-Aldrich, St. Louis) and sequenced using Genome Sequencer Illumina HiSeq2500 technology (GATC Biotech). Total of 6,364,797 high quality filtered paired-end reads of length 126 bp were generated (Bokulich et al. 2013). SPAdes was used to assemble the filtered reads (Bankevish et al. 2014). Tools are available at the Galaxy portal of the MIGALE platform. The obtained contigs were ordered using Mauve genome alignment software v2.1.3 (Darling et al. 2004), and assemblies were manually combined in one contig with a total size of 4,23 $\mathrm{Mb}$ by identifying overlapping nucleotide sequences in reads and mapping them against genomes of the closest B. velezensis strains CC09 (accession $n^{\circ}$ : NZ_CP015443), CFSAN034339 (accession $n^{\circ}$ : LYNB00000000) and Bs006 (accession $n^{\circ}$ : NZ_LJAU00000000). Genome annotation was accomplished using the NCBI Prokaryotic Genomes Automatic Annotation Pipeline (PGAAP) (Angiuoli et al. 2008).

The strain QST713 was known as Bacillus subtilis QST713 in previous studies (Patel et al. 2011; Lahlali et al. 2013). However, based on the comparative phylogenomic analysis of Bacillus genomes (Table 1; Fig. 1), the QST713 strain initially designated as Bacillus subtilis 
should be now reassigned as Bacillus velezensis species (formerly known as Bacillus amyloliquefaciens subsp. plantarum, (Fan et al. 2017)). Indeed, digital DNA-DNA Hybridization (dDDH), average nucleotide or amino acid identity (ANI/AAI) analyses showed a higher similarity of the QST713 strain with Bacillus velezensis species than other Bacillus species (Table 1). The genomic structure of the B. velezensis QST713 chromosome of 4,233,757 bp length and a Blast comparison with B. subtilis and B. velezensis strain are represented in Fig. 2. The genome sequence has a $\mathrm{G}+\mathrm{C}$ content of $45,9 \%$ and 4263 predicted genes, including 4056 coding sequences (CDS), 98 pseudo genes, 25 rRNA , 79 tRNA and 5 ncRNA genes. The classification of the QST713 genes into clusters of orthologous groups (COG) assigned 2909 CDS in at least one COG group (71.7\%) (Fig. S1). 1147 CDS were not classified into COG. In those 1147 CDS, 602 were assigned to hypothetical proteins and 545 were conserved proteins, most are parts of prophage regions or involved in sporulation and putative secondary metabolites synthesis. $21 \%$ of all assigned COG CDS was dedicated to the transport and metabolism of amino acids, carbohydrates, lipids, inorganic ions, the defence mechanisms and the biosynthesis, transport and catabolism of secondary metabolites. These functions are essentials for a biocontrol agent in terms of nutritional/spatial competition and antagonism against microorganisms to colonize and compete in various ecosystems. PHASTER analysis of B. velezensis QST713 genome identified six prophage regions (Table S1) depicted on the red ring in Fig. 2, which represent $8 \%$ of the entire genome. These regions correspond to variable regions which can be visualized in Fig. 2 (rings 8 to 11) when comparing the genome of B. velezensis QST713 with other Bacillus genomes, indicating a strong genomic plasticity of the QST713 strain.

\section{Secondary metabolite clusters}


Through the antiSMASH genome analysis tool, fifteen clusters of secondary metabolites

101 have been identified in the genome of the QST713 strain (Table 2; Fig. 2), five encoding NRPS (Non-Ribosomal Peptide Synthetase), two transATPKS (trans-Acyl Transferase Polyketide Synthetase), three transATPKS-NRPS, two terpene, one lantipeptide, one T3PKS

104 and one otherKS. Nine clusters have been clearly identified as being involved in the synthesis 105 of surfactin, macrolactin, bacillaene, bacillomycin D, fengycin, difficidin, bacilysin, subtilin106 like/ericin and bacillibactin (siderophore). All have antimicrobial/antibacterial activities or are 107 implicated in antibiosis (Stein et al. 2002, 2005; Ongena et al. 2005; Ongena and Jacques 108 2008; Chen et al. 2009; Niazi et al. 2014). This analysis revealed that at least $12 \%$ of the 109 QST713 genome is allocated to the biosynthesis, regulation and transport of antimicrobials. 110 Secondary metabolites clusters have been compared to four Bacillus strains (FZB42, SQR9, 111 NCIB3610 and 168) (Table 2). For all fifteen clusters, genes have been verified, detailed and 112 compared to the reference strain B. velezensis FZB42, or when genes were absent from 113 FZB42 strain, to B. velezensis CC09 and Bacillus subtilis A13 (Table S2). The arrangement of 114 gene clusters in B. velezensis QST713 is very similar to those in FZB42 (98-99\% nucleotide 115 identity) (Fig. 3; Table S2). Bacillus velezensis QST713 has three clusters that are not present 116 in all four Bacillus strains (Table 2; Fig. 3). The cluster ten responsible for the synthesis of 117 subtilin-like/ericin (Genbank accession number AF233755.1) and not present in FZB42, is 118 found in Bacillus subtilis A13 (unpublished genome) (Stein et al. 2002; 2005). We found two 119 clusters encoding potential novel metabolites and not yet described that are similar to gene 120 clusters in CC09 (Fig. 3; Table 2; Table S2). The cluster nine encoding TransATPKS-NRPS 121 shows $22 \%$ of gene similarity with rhizocticin, but the biosynthetic genes of the QST713 122 strain in this cluster do not correspond to rhizocticin biosynthetic genes from the MIBiG 123 database. In the same way, the cluster eleven encoding NRPS is also unknown from MIBiG 
124 database (Fig. 3; Table 2; Table S2). In accordance with Cai et al. 2017 study, these two

125 clusters could encode two new metabolites specific to B. velezensis species.

\section{Biofilm phenotypes and swarming motility}

B. velezensis QST713 is provided with a large number of genes involved in the biofilm formation process (Table 3). Indeed, it has two operons involved in the synthesis of

130 extracellular polysaccharides, epsA-O operon and capABC (pgsABC) operon. It also has the 131 tasA-sipW-tapA operon that codes for the TasA protein forming amyloid fibres (Table 3) (de

132 Jong et al. 2009; Romero et al. 2010). These genes are regulated by a large number of 133 regulatory genes such as $\operatorname{spoOA}, \operatorname{rem} A, \sin I / \sin R, \operatorname{sig} W, a b r B$ described in $B$. subtilis and also 134 present in B. velezensis QST713 (Winkelman et al. 2009; Vlamakis et al. 2013). Indeed, the 135 QST713 strain shows a complex macrocolony structure which is mucoid under a thick and dry surface layer as compared to B. subtilis 168 which has flat and non-mucoid macrocolony (Fig. 4). B. velezensis SQR9 also shows complex structure but without mucoid aspect. However, B. velezensis FZB42 which also harbours these matrix genes shows a flat macrocolony. We obtain the same results for pellicles experiment with a thick and solid

140 pellicle for QST713 strain compared to other strains (Fig. 4). The biofilm experiment shows,

141 like macrocolonies and pellicles experiments, more structured and denser cellular aggregates

142 for QST713 strain than for other strains capable of forming biofilms (Fig. 4). As observed by

143 Magno-Pérez-Bryan et al. 2015 and Norman et al. 2013, our results show that despite having

144 biofilm and regulatory genes, it may be possible that other regulatory pathways or epigenetics 145 event are involved in biofilm formation and related phenotype expressions.

146 Swarming motility is an essential skill to colonize environmental surfaces such as soils or 147 crops tissues (Fan et al. 2011; Mordini et al. 2013). B. velezensis QST713 has the swr genes 148 necessary for swarming motility but also the fla-che operon including fla genes that code for 
149 flagellar components and are up-regulated by swrA, thus improving swarming motility

150 (Kearns et al. 2004; Ghelardi et al. 2012). All the strains tested except the negative swarming 151 control B. subtilis 168 showed a swarming motility characterized by the invasion of $9 \mathrm{~cm}$ 152 diameters of TSA $0.8 \%$ agar plates at $25^{\circ} \mathrm{C}$ in 24 hours (Fig. 4). Efficient swarming and 153 biofilm formation confer to biocontrol agents a better fitness to colonize substrata and to 154 outcompete pathogens.

155

\section{Biocontrol effect of B. velezensis QST713 against the green mould T. aggressivum}

Biocontrol assay with B. velezensis QST713 in the mushroom field and antagonism tests by measuring inhibition zones surrounding Bacillus strains were performed (Fig. 5). Biocontrol assay was carried out from November 2017 to January 2018 at the technical mushroom center (CTC, Distré, France). Results show a strong effect of the QST713 strain on the yield of $A$. bisporus crops infected by T. aggressivum. When the culture compost is contaminated by T. aggressivum, we observed a diminution of the yield of A. bisporus for about $50 \%$ (Fig. 5A). However, when the compost contaminated is treated by the QST713

164 strain, the yield of A. bisporus returned to a value similar to the control yield (Fig. 5A).

165 Furthermore, antagonism test by B. velezensis QST713 shows a strong efficacy against the 166 green mould by a direct inhibition (inhibition zone: $4.7 \pm 0.5 \mathrm{~mm}$ ) of the growth of mycelium and an inhibition of fungus sporulation (diminution of green colour) compared to $T$. aggressivum alone (Fig. 5B(a),(b)). This second antagonism effect which is not located at the

169 direct interaction interface, could be due to a secretion of volatile organic compounds by the

170 QST713. This phenomenon has already been demonstrated on the inhibition of sporulation of 171 Streptomyces scabies (Meng et al. 2016).

\section{Conclusion}


The phylogenetic analysis of the QST713 genome allows to reassign the strain QST713 as

175 a Bacillus velezensis strain. Its ability to form highly structured, thick and dense biofilms in

176 vitro and its ability to swarm on agar plates supposedly allow its efficient colonization and

177 persistence in crops. In addition, it is equipped with an antimicrobial battery enabling it to

178 fight with aggressors, including ericin as well as potentially one NRPS and one transATPKS-

179 NRPS not yet characterized and found only in few B. velezensis. All these features allow $B$.

180 velezensis QST713 to be highly competitive in the environment and makes it a particularly

181 efficient biocontrol agent.

182

\section{Nucleotide sequence accession numbers}

184 The complete genome sequence of B. velezensis QST713 has been deposited in NCBI under 185 the GenBank accession number CP025079.

186

\section{Acknowledgements}

188

C. Pandin is granted a doctoral fellowship by the Ile-de-France Region, DIM ASTREA

189 (project $\mathrm{n}^{\circ}$ ast150075). We thank the MIMA2 platform (www6.jouy.inra.fr/mima2) for

190 accessing to LeicaSP8. We thank R. Borriss and R. Zhang for providing the Bacillus

191 amyloliquefaciens FZB42 and SQR9 strains, respectively. We are grateful to the EDGAR

192 (https://edgar.computational.bio.uni-giessen.de/) and INRA MIGALE

193 (http://migale.jouy.inra.fr) bioinformatics platforms for providing computational resources.

194

195 References

196 Abd El Daim, I., Häggblom, P., Karlsson, M., Stenström, E., Timmusk, S., 2015.

197 "Paenibacillus polymyxa A26 Sfp-Type PPTase inactivation limits bacterial antagonism 
against Fusarium graminearum but not of F. culmorum in kernel assay." Frontiers in Plant Science 6: 368. doi:10.3389/fpls.2015.00368.

Alikhan, N.-F., Petty, N.K., Ben Zakour, N.L., Beatson, S.A., 2011. "BLAST Ring Image (August): 402. doi:10.1186/1471-2164-12-402.

Angiuoli, S.V., Gussman, A., Klimke, W., Cochrane, G., Field, D., Garrity, G.M., Kodira, C.D., Kyrpides, N., Madupu, R., Markowitz, V., Tatusova, T., Thomson, N., White, O., 2008. « Toward an online repository of Standard Operating Procedures (SOPs) for (Meta) genomic annotation ». OMICS: a Journal of Integrative Biology 12 (2):137- 41. doi:10.1089/omi.2008.0017.

Arndt, D., Grant, J.R., Marcu, A., Sajed, T., Pon, A., Liang, Y., Wishart, D.S., 2016. "PHASTER: a better, faster version of the PHAST phage search tool." Nucleic Acids Research 44 (W1): W16-21. doi:10.1093/nar/gkw387.

Bankevich, A., Nurk, S., Antipov, D., Gurevich, A.A., Dvorkin, M., Kulikov, A.S., Lesin, V.M., Nikolenko, S.I., Pham, S., Prjibelski, A.D., Pyshkin, A.V., Sirotkin, A.V., Vyahhi, N., Tesler, G., Alekseyev, M.A., Pevzner, P.A., 2012. "SPAdes: a new genome assembly algorithm and its applications to single-cell sequencing." Journal of Computational Biology: A Journal of Computational Molecular Cell Biology 19 (5): 455-77. doi:10.1089/cmb.2012.0021.

Blin, K., Medema, M.H., Kazempour, D., Fischbach, M.A., Breitling, R., Takano, E., Weber, T., 2013. antiSMASH 2.0 - a versatile platform for genome mining of secondary metabolite producers. Nucleic Acids Res. 41, W204-W212. doi:10.1093/nar/gkt449.

Blom, J., Albaum, S.P., Doppmeier, D., Pühler, A., Vorhölter, F.-J., Zakrzewski, M., Goesmann, A., 2009. "EDGAR: a software framework for the comparative analysis of 
prokaryotic genomes.” BMC Bioinformatics 10 (May): 154. doi:10.1186/1471-2105-10154.

224 Blom, J., Kreis, J., Spänig, S., Juhre, T., Bertelli, C., Ernst, C., Goesmann, A., 2016. "EDGAR 2.0: an enhanced software platform for comparative gene content analyses." Nucleic Acids Research 44 (W1): W22-28. doi:10.1093/nar/gkw255.

Bokulich, N.A., Subramanian, S., Faith, J.J., Gevers, D., Gordon, J.I., Knight, R., Mills, D.A., Caporaso, J.G., 2013. Quality-filtering vastly improves diversity estimates from Illumina amplicon sequencing. Nat. Methods 10, 57-59. doi:10.1038/nmeth.2276.

Borriss, R., 2015. "Bacillus, a plant-beneficial bacterium.” In Principles of Plant-Microbe Interactions: Microbes for Sustainable Agriculture, edited by Ben Lugtenberg, 379-91. Cham: Springer International Publishing. doi:10.1007/978-3-319-08575-3_40.

Cai, X.-C., Liu, C.-H., Wang, B.-T., Xue, Y.-R., 2017. "Genomic and metabolic traits endow Bacillus velezensis CC09 with a potential biocontrol agent in control of wheat powdery mildew disease." Microbiological Research $196 \quad$ (March): 89-94. doi:10.1016/j.micres.2016.12.007.

Cawoy, H., Debois, D., Franzil, L., De Pauw, E., Thonart, P., Ongena, M., 2015. 7915.12238 .

Chen, X.H., Koumoutsi, A., Scholz, R., Schneider, K., Vater, J., Süssmuth, R., Piel, J., Borriss, R., 2009. "Genome analysis of Bacillus amyloliquefaciens FZB42 reveals its potential for biocontrol of plant pathogens." Journal of Biotechnology, Functional Genome Research on Bacteria Relevant for Agriculture, Environment and Biotechnology Functional Genome Research, 140 (1-2): 27-37. doi:10.1016/j.jbiotec.2008.10.011. 
Costerton, J.W., Geesey, G.G., Cheng, K.J., 1978. "How bacteria stick.” Scientific American 238 (1): 86-95.doi: 10.1038/scientificamerican0178-86.

Costerton, J.W., Stewart, P.S., Greenberg, E.P., 1999. "Bacterial biofilms: a common cause of persistent infections.” Science 284 (5418): 1318-22. doi:10.1126/science.284.5418.1318.

Darling, A.C.E., Mau, B., Blattner, F.R., Perna, N.T., 2004. "Mauve: multiple alignment of conserved genomic sequence with rearrangements." Genome Research 14 (7): 13941403. doi:10.1101/gr.2289704.

Edgar, R.C., 2004a. « MUSCLE: multiple sequence alignment with high accuracy and high throughput ». Nucleic Acids Research 32 (5):1792- 97. doi:10.1093/nar/gkh340.

Edgar, R.C., 2004b. «MUSCLE: a multiple sequence alignment method with reduced time and space complexity ». BMC Bioinformatics 5 (août):113. doi:10.1186/1471-2105-5-

Epstein, A.K., Pokroy, B., Seminara, A., Aizenberg, J., 2011. "Bacterial biofilm shows persistent resistance to liquid wetting and gas penetration." Proceedings of the National Academy of Sciences 108 (3): 995-1000. doi:10.1073/pnas.1011033108.

Fan, B., Chen, X.H., Budiharjo, A., Bleiss, W., Vater, J., Borriss, R., 2011. "Efficient 262 colonization of plant roots by the plant growth promoting bacterium Bacillus amyloliquefaciens FZB42, Engineered to Express Green Fluorescent Protein.” Journal of Biotechnology 151 (4): 303-11. doi:10.1016/j.jbiotec.2010.12.022.

Fan, B., Blom, J., Klenk, H.-P., Borriss, R., 2017. “Bacillus amyloliquefaciens, Bacillus velezensis, and Bacillus siamensis form an 'operational group B. amyloliquefaciens' within the B. subtilis species complex." Frontiers in Microbiology 8. doi:10.3389/fmicb.2017.00022.

Ghelardi, E., Salvetti, S., Ceragioli, M., Gueye, S.A., Celandroni, F., Senesi, S., 2012. 
motility in Bacillus subtilis." Applied and Environmental Microbiology 78 (18): 6540-44. doi:10.1128/AEM.01341-12.

273 Goris, J., Konstantinidis, K.T., Klappenbach, J.A., Coenye, T., Vandamme, P., Tiedje, J.M., 2007. DNA-DNA hybridization values and their relationship to whole-genome sequence similarities. Int. J. Syst. Evol. Microbiol. 57, 81-91. https://doi.org/10.1099/ijs.0.64483-0.

Gouy, M., Guindon, S., Gascuel, O., 2010. "SeaView version 4: a multiplatform graphical user interface for sequence alignment and phylogenetic tree building." Molecular Biology and Evolution 27 (2): 221-24. doi:10.1093/molbev/msp259.

de Jong, W., Wösten, H.A.B., Dijkhuizen, L., Claessen, D., 2009. "Attachment of Streptomyces coelicolor is mediated by amyloidal fimbriae that are anchored to the cell surface via cellulose.” Molecular Microbiology 73 (6): 1128-40. doi:10.1111/j.13652958.2009.06838.x.

Jones, C.J., Wozniak, D.J., 2017. « Congo red stain identifies matrix overproduction and is an indirect measurement for c-Di-GMP in many species of bacteria ». In C-Di-GMP Signaling, 147- 156. Methods in Molecular Biology. Humana Press, New York, NY. doi:10.1007/978-1-4939-7240-1_12.

Joshi, R., McSpadden Gardener, B.B., 2006. «Identification and characterization of novel genetic markers associated with biological control activities in Bacillus subtilis». Phytopathology 96 (2):145- 54. doi:10.1094/PHYTO-96-0145.

Kearns, D.B., Chu, F., Rudner, R., Losick, R., 2004. “Genes governing swarming in Bacillus subtilis and evidence for a phase variation mechanism controlling surface motility." Molecular Microbiology 52 (2): 357-69. doi:10.1111/j.1365-2958.2004.03996.x.

Lahlali, R., Peng, G., Gossen, B.D., McGregor, L., Yu, F.Q., Hynes, R.K., Hwang, S.F., McDonald, M.R., Boyetchko, S.M., 2013. "Evidence that the biofungicide serenade 
(Bacillus subtilis) suppresses clubroot on canola via antibiosis and induced host resistance.” Phytopathology 103 (3): 245-54. doi:10.1094/PHYTO-06-12-0123-R.

Largeteau, M.L., Savoie, J.-M., 2010. "Microbially Induced Diseases of Agaricus Bisporus: biochemical mechanisms and impact on commercial mushroom production." Applied Microbiology and Biotechnology 86 (1): 63-73. doi:10.1007/s00253-010-2445-2.

Magno-Pérez-Bryan, M.C., Martinez-Garcia, P.M., Hierrezuelo, J., Rodriquez-Palenzuela, P., 301 "Comparative genomics within the Bacillus genus reveal the singularities of two robust Bacillus amyloliquefaciens biocontrol strains." Molecular Plant-Microbe Interactions: MPMI, June. doi:10.1094/MPMI-02-15-0023-R.

Mamoun, M.L., Iapicco, R., Savoie, J.M., Olivier, J.M., 2000. “Green mould disease in France: Trichoderma harzianum Th2 and other species causing damages on mushroom farms." In Sci. Cultiv. of Edible Fungi. Edited by L. Van Griensven. Balkema, Rotterdam. 625-632.

Medema, M.H., Blin, K., Cimermancic, P., de Jager, V., Zakrzewski, P., Fischbach, M.A., Weber, T., Takano, E., Breitling, R., 2011. antiSMASH: rapid identification, annotation and analysis of secondary metabolite biosynthesis gene clusters in bacterial and fungal genome sequences. Nucleic Acids Res. 39, W339-W346. doi:10.1093/nar/gkr466.

Meier-Kolthoff, J.P., Auch, A.F., Klenk, H.-P., Göker, M., 2013. Genome sequence-based species delimitation with confidence intervals and improved distance functions. BMC Bioinformatics 14, 60. doi:10.1186/1471-2105-14-60.

Meng, Q., Jiang, H., Hao, J.J., 2016. "Effects of Bacillus velezensis strain BAC03 in promoting plant growth". Biological Control 98 (Supplement C):18-26. doi:10.1016/j.biocontrol.2016.03.010. 
Mordini, S., Osera, C., Marini, S., Scavone, F., Bellazzi, R., Galizzi, A., Calvio, C., 2013. "The role of SwrA, DegU and P(D3) in fla/che expression in B. subtilis." PloS One 8 (12): e85065. doi:10.1371/journal.pone.0085065.

Morris, C.E., Monier, J.-M., 2003. “The ecological significance of biofilm formation by plantassociated bacteria." Annual Review of Phytopathology 41: 429-53. doi: 10.1146/annurev.phyto.41.022103.134521.

Niazi, A., Manzoor, S., Asari, S., Bejai, S., Meijer, J., Bongcam-Rudloff, E., 2014. “Genome analysis of Bacillus amyloliquefaciens subsp. plantarum UCMB5113: a rhizobacterium that improves plant growth and stress management." PloS One 9 (8): e104651. doi:10.1371/journal.pone.0104651.

Norman, T.M., Lord, N.D., Paulsson, J., and Losick, R. 2013. "Memory and Modularity in Cell-Fate Decision Making”. Nature 503 (7477): 481-86. doi:10.1038/nature12804.

Ongena, M., Jacques, P., 2008. “Bacillus lipopeptides: versatile weapons for plant disease biocontrol." Trends in Microbiology 16 (3): 115-25. doi:10.1016/j.tim.2007.12.009.

Ongena, M., Jacques, P., Touré, Y., Destain, J., Jabrane, A., Thonart, P., 2005. “Involvement of fengycin-type lipopeptides in the multifaceted biocontrol potential of Bacillus Subtilis." Applied Microbiology and Biotechnology 69 (1): 29-38. doi:10.1007/s00253005-1940-3.

Pandin, C., Le Coq, D., Canette, A., Aymerich, S., Briandet, R., 2017. "Should the biofilm mode of life be taken into consideration for microbial biocontrol agents?" Microbial Biotechnology, February, 10(4): 719-734. doi:10.1111/1751-7915.12693.

Patel, H., Tscheka, C., Edwards, K., Karlsson, G., Heerklotz, H., 2011. “All-or-none membrane permeabilization by fengycin-type lipopeptides from Bacillus subtilis QST713.” Biochimica Et Biophysica Acta $1808 \quad$ (8): 2000-2008. doi:10.1016/j.bbamem.2011.04.008. 
344 Punja, Z.K., Rodriguez, G., Tirajoh, A., 2016. «Effects of Bacillus subtilis strain QST 713 and storage temperatures on post-harvest disease development on greenhouse tomatoes ». Crop Protection 84 (juin):98- 104. doi:10.1016/j.cropro.2016.02.011.

Rodriguez-R, L.M., Konstantinidis, K.T., 2016. The enveomics collection: a toolbox for specialized analyses of microbial genomes and metagenomes. PeerJ Prepr. 4, e1900v1. doi:10.7287/peerj.preprints.1900v1.

350 Romero, D., Aguilar, C., Losick, R., Kolter, R., 2010. “Amyloid fibers provide structural integrity to Bacillus subtilis biofilms.” Proceedings of the National Academy of Sciences 107 (5): 2230-34. doi:10.1073/pnas.0910560107.

Samuels, G.J., Dodd, S.L., Gams, W., Castlebury, L.A., Petrini, O., 2002. "Trichoderma species associated with the green mold epidemic of commercially grown Agaricus bisporus." Mycologia 94 (1): 146-70. doi: 10.2307/3761854

Stein, T., Borchert, S., Conrad, B., Feesche, J., Hofemeister, B., Hofemeister, J., Entian, K.-

Stein, T., 2005. "Bacillus subtilis antibiotics: structures, syntheses and specific functions." Molecular Microbiology 56 (4): 845-57. doi:10.1111/j.1365-2958.2005.04587.x.

Vlamakis, H., Chai, Y., Beauregard, P., Losick, R., Kolter, R., 2013. "Sticking together:

Weber, T., Blin, K., Duddela, S., Krug, D., Kim, H.U., Bruccoleri, R., Lee, S.Y., Fischbach, M.A., Müller, R., Wohlleben, W., Breitling, R., Takano, E., Medema, M.H., 2015. antiSMASH 3.0 - a comprehensive resource for the genome mining of biosynthetic gene clusters. Nucleic Acids Res. 43, W237-W243. doi:10.1093/nar/gkv437. 
Winkelman, J.T., Blair, K.M., Kearns, D.B., 2009. “RemA (YlzA) and RemB (YaaB) regulate extracellular matrix operon expression and biofilm formation in Bacillus subtilis." Journal of Bacteriology 191 (12): 3981-91. doi:10.1128/JB.00278-09.

Wu, S., Zhu, Z., Fu, L., Niu, B., Li, W., 2011. "WebMGA: a customizable web server for fast metagenomic sequence analysis." BMC Genomics 12 (September): 444. doi:10.1186/1471-2164-12-444.

Xu, Z., Zhang, R., Wang, D., Qiu, M., Feng, H., Zhang, N., Shen, Q., 2014. "Enhanced control of cucumber wilt disease by Bacillus amyloliquefaciens SQR9 by altering the regulation of its degu phosphorylation." Applied and Environmental Microbiology 80 (9): 2941-50. doi:10.1128/AEM.03943-13.

Yoon, S.-H., Ha, S.-M., Lim, J., Kwon, S., Chun, J., 2017. A large-scale evaluation of algorithms to calculate average nucleotide identity. Antonie Van Leeuwenhoek 110, 1281-1286. doi :10.1007/s 10482-017-0844-4.

Zeriouh, H., de Vicente, A., Pérez-García, A., Romero, D., 2014. "Surfactin triggers biofilm formation of Bacillus subtilis in melon phylloplane and contributes to the biocontrol activity." Environmental Microbiology $16 \quad$ (7): 2196-2211. doi:10.1111/14622920.12271 .

Zhao, X., Kuipers, O.P., 2016. "Identification and classification of known and putative antimicrobial compounds produced by a wide variety of Bacillales species." $B M C$ Genomics 17: 882. doi:10.1186/s12864-016-3224-y.

Zhou, Y., Liang, Y., Lynch, K.H., Dennis, J.J., Wishart, D.S., 2011. "PHAST: a fast phage search tool." Nucleic Acids Research 39 (Web Server issue): W347-352. doi:10.1093/nar/gkr485. 


\section{TABLE AND FIGURE LEGENDS}

402

Table 1: Comparative genomic analysis of Bacillus velezensis QST713 with Bacillus 404 genomes. (Footnote: Average nucleotide identity (ANI) and average amino acid identity 405 (AAI) calculation was performed via the EDGAR platform and the Kostas lab web server 406 (Blom et al. 2009, 2016; Goris et al. 2007; Rodriguez-R \& Konstantinidis 2016; Yoon et al. 407 2017). Digital DNA-DNA hybridization (dDDH) calculation was performed through the 408 DSMZ webserver, the genome-to-genome-distance calculator version 2.1 (GGDC) was used 409 for genome-based species delineation (Meier-Kolthoff et al. 2013) with formula two as 410 described in Fan et al. 2017.)

411

412 Table 2: Comparative analysis of secondary metabolites clusters of Bacillus velezensis 413 QST713 identified in genome with plant-associated strains and reference genomes.

414 (Footnote: Prediction of secondary metabolites clusters of Bacillus strains were performed 415 through the antiSMASH web server (Medema et al. 2011; Blin et al. 2013; Weber et al. 416 2015). 
418 Table 3: Comparative analysis of genes involved in biofilm formation in B. velezensis 419 QST713 and B. velezensis FZB42. (*) represents the longest nucleotide sequence taken as a 420 basis for BLAST comparison.

422 Table S1: Prophage regions of Bacillus velezensis QST713 genome.

423 (Footnote: Prophage regions were identified using PHASTER web server (Zhou et al. 2011; 424 Arndt et al. 2016).

Table S2: Comparative analysis of gene clusters encoding secondary metabolites in $B$. velezensis QST713 with Bacillus strains. (*) represents the longest nucleotide sequence taken as a basis for BLAST comparison.

Fig. 1: Neighbor-joining phylogenetic tree constructed from the core genomes of $30 \mathrm{~B}$. subtilis, B. amyloliquefaciens and B. velezensis strains. The position of Bacillus velezensis QST713 in the tree is marked by a yellow dot. EDGAR platform was used to obtain 433 alignements in NEXUS format and SeaView 4.5.4 software to construct phylogenetic tree 434 using maximum-parsimony method (Edgar 2004a, 2004b; Blom et al. 2009, 2016; Gouy et al. 435 2009).

437 Fig. 2: Circular map of genomic features of the whole genome of Bacillus velezensis QST713. 438 Circles display from the inner to outside: (1) GC Skew ; (2) GC Content ; (3) Predictive 439 secondary metabolites clusters ; (4) Predictive prophages clusters; (5) rRNA (black), tRNA 440 (red), ncRNA (green); (6) Predicted CDSs transcribed in clockwise direction; (7) Predicted 441 CDSs transcribed in the counterclockwise direction; $(8,9,10,11)$ Blast comparison of 442 QST713 genome with Bacillus strains, SQR9, FZB42, NCIB3610 and 168 respectively. 
443 Circular map and blast comparison were performed with BLAST Ring Image Generator 444 software (BRIG) (Alikhan et al. 2011).

446 Fig. 3: Blast comparison of NRPS, TransATPKS and lantipeptide clusters in QST713 447 (above), FZB42, A13 or CC09 (below). Square indicate the differences between strain 448 sequences.

Fig. 4: Phenotypic comparisons of B. velezensis QST713 with Bacillus species. Strains are B. subtilis 168, B. subtilis NCIB3610, B. velezensis SQR9, B. velezensis FZB42 and B. velezensis QST713. Biofilm formation was evaluated as macrocolonies morphology, pellicles formation and submerged biofilms. To visualize colony architecture, $5 \mu \mathrm{l}$ of an overnight culture in TSB were spotted on 1.5\% Tryptone Soya Agar (TSA, Biomérieux, France) with 40 $\mu \mathrm{g} \cdot \mathrm{ml}^{-1}$ of Congo red to visualize matrix elements (Jones and Wozniak 2017). For pellicles visualisation, $10 \mu \mathrm{l}$ of an overnight culture in TSB were used to inoculate $2 \mathrm{ml}$ of TSB in 24well plates (TPP, Switzerland). Plates were then incubated at $25^{\circ} \mathrm{C}$ for $72 \mathrm{~h}$, macrocolonies and pellicles formation were recorded at $72 \mathrm{~h}$ and digital pictures were taken. Submerged biofilm formation was performed in 96-well microtiter plates (Greiner $\mu$ Clear ${ }^{\circledR}$, Germany).

460 Briefly, for each strain, $200 \mu \mathrm{l}$ of an overnight culture in TSB standardized to an $\mathrm{OD}_{600 \mathrm{~nm}}$ of 0.01 were added to the wells, then incubated at $25^{\circ} \mathrm{C}$ for $90 \mathrm{~min}$ for attachment. The supernatant was removed to eliminate non-adherent bacteria and $200 \mu \mathrm{l}$ of sterile TSB was 463 added. Plates were then incubated for $24 \mathrm{~h}$ at $25^{\circ} \mathrm{C}$, experiment was repeated six times. 464 SYTO9® (Invitrogen, France), a green-fluorescent nucleic acid marker was used to tag the cells fluorescently for submerged-biofilm observations by confocal laser scanning microscopy 466 (Leica SP8, Leica Mycrosystems, Germany). Swarming motility of Bacillus strains was 467 determined by the spread of bacteria on TSA $0.8 \%$ agar plates at $25^{\circ}$ for $24 \mathrm{~h}, 10 \mu \mathrm{l}$ of an 
overnight culture were inoculated at the centre of the $9 \mathrm{~cm}$ agar plates dried for $15 \mathrm{~min}$ and incubated at $25^{\circ} \mathrm{C}$ for $24 \mathrm{~h}$. Experiments was repeated three times.

Fig. 5: Biocontrole effect of Bacillus velezensis QST713 against T. aggressivum f. europaeum. (A) Button mushroom yields of A. bisporus when the culture compost is contaminated or not by T. aggressivum (T. a) and treated or not by the QST713 strain: (+) Presence of; (-) Absence of. Agaricus bisporus was seeded at a rate of $0,8 \%$ of compost weight (Amycel Delta, white hybrid variety, Amycel, Vendôme). Treatment with $B$. velezensis QST713: compost was homogenized with suspension of B. velezensis QST713 at a rate of 0.1 g. $\mathrm{kg}^{-1}$ of product (Serenade Max $®$, AMM No. 2100162, BayerCropScience, France) corresponding at $5.10^{6} \mathrm{CFU}_{\text {gr }}{ }^{-1}$ of compost. Inoculation with $T$. aggressivum with 2000 spores in a central spot in pot of $9 \mathrm{~kg}$ of compost. Yield data correspond at the number in $\mathrm{kg}$ per $\mathrm{m}^{2}$ of button mushroom whole feets collected form a complete culture cycle of 2 months. Experiment was repeated 6 times. (B) Antagonism test of T. aggressivum by $B$. velezensis QST713: (a) T. aggressivum alone; (b) T. aggressivum vs B. velezensis QST713. The fungal pathogen was inoculated with an agar plug taken from a $72 \mathrm{~h}$ fungal culture that was deposited on the center of YMEA medium plate (yeast extract $2 \mathrm{~g} . \mathrm{L}^{-1}$, malt extract 20g.L 1, agar $15 \mathrm{~g} . \mathrm{L}^{-1}$ ). $5 \mu \mathrm{l}$ of sterile water (control) or of an overnight culture of B. velezensis QST713 in TSB was inoculated in three spots at $3 \mathrm{~cm}$ of T. aggressivum spot. Petri dish were incubated at $25^{\circ} \mathrm{C}$ and observations are performed 5 days after by measuring the inhibition zone of T. aggressivum. Experiment was repeated 3 times. Differences among treatments were determined by performing a one-way analysis of variance $(P<0.05)$ and Tukey's honestly significant difference (HSD) procedure $(P<0.05)$ with Statgraphics Centurion software (Statpoint Technologies, United States). Letters a and b on the graph represent significant differences $(P<0.05)$. 
494 Fig. S1: Classification of genes into orthologous groups (COG) in B. velezensis QST713. 495 Distribution of B. velezensis QST713 coding sequences (71.7\%) symbolized in percentages of 496 genes classified into COG. Genes not found in the cog annotation are classified in the 497 category "not in COG" in black. The functional classification of protein-coding genes was 498 performed using RPS-BLAST with COG database and classified into categories via the 499 WebMGA server (Wu et al. 2011).

500

501 
Table 1: Comparative genomic analysis of Bacillus velezensis QST713 with Bacillus genomes.

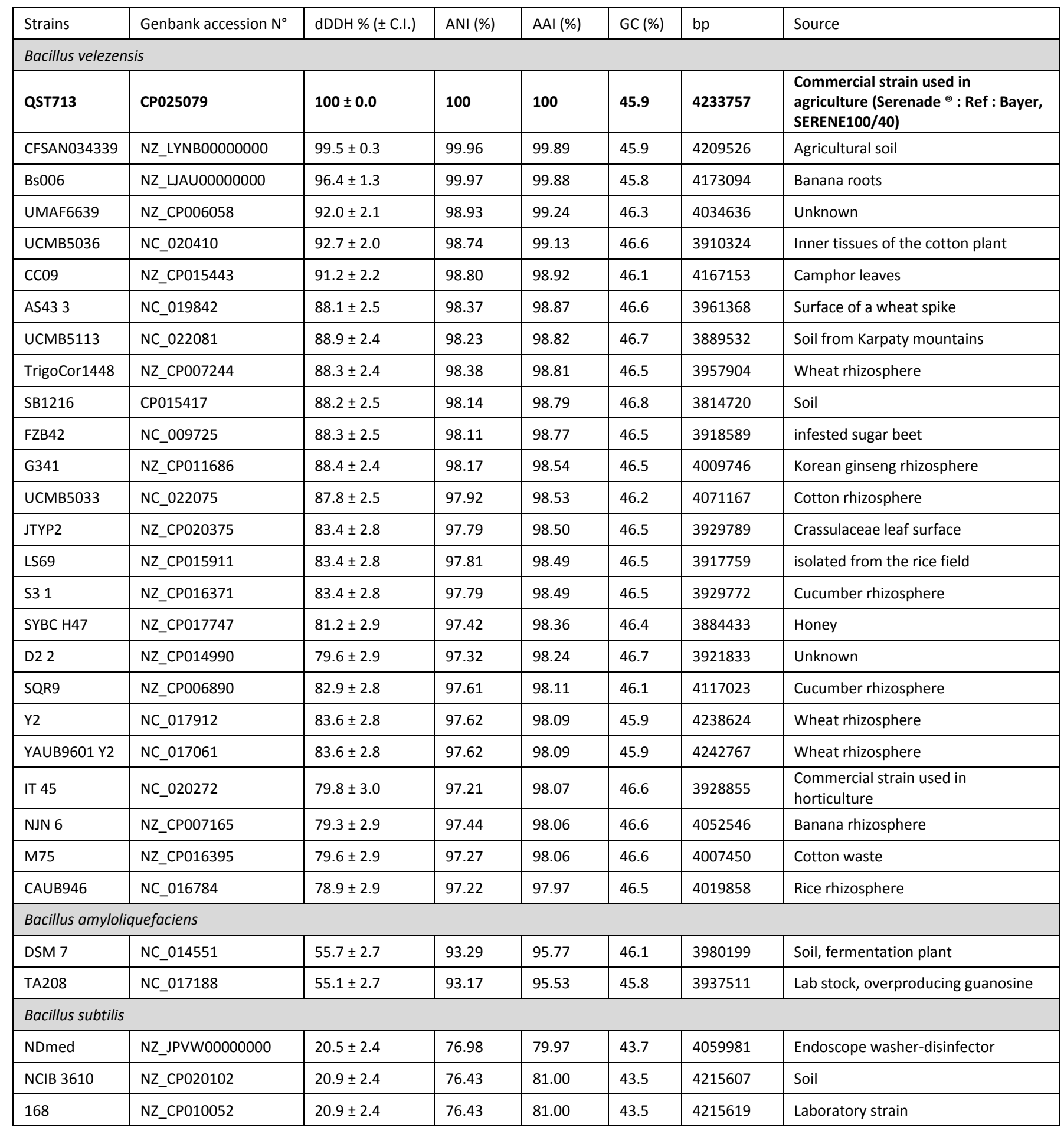

(Footnote: Average nucleotide identity (ANI) and average amino acid identity (AAI) calculation was performed via the EDGAR platform and the Kostas lab web server (Blom et al. 2009, 2016; Goris et al. 2007; Rodriguez-R \& Konstantinidis 2016; Yoon et al. 2017). Digital DNA-DNA hybridization $(\mathrm{dDDH})$ calculation was performed through the DSMZ webserver, the genome-to-genome-distance calculator version 2.1 (GGDC) was used for genome-based species delineation (Meier-Kolthoff et al. 2013) with formula two as described in Fan et al. 2017.) 
Table 2: Comparative analysis of secondary metabolites clusters of Bacillus velezensis QST713 identified in genome with plant-associated strains and reference genomes.

\begin{tabular}{|c|c|c|c|c|c|c|c|c|c|}
\hline \multicolumn{6}{|c|}{ Bacillus velezensis QST713 } & \multicolumn{4}{|c|}{$\begin{array}{l}\text { Presence }(+) \text { or absence }(-) \text { of secondary } \\
\text { metabolites clusters in Bacillus strains }\end{array}$} \\
\hline $\begin{array}{l}\text { Cluster } \\
\text { number }\end{array}$ & Synthetase & Metabolites & $\begin{array}{l}\text { MIBiG ID (\% of genes } \\
\text { show similarity) }\end{array}$ & $\begin{array}{l}\text { Predicted large } \\
\text { cluster position }\end{array}$ & bp & FZB42 & SQR9 & 3610 & 168 \\
\hline 1 & NRPS & Surfactin & BGC0000433_c1 (86\%) & $347609-413022$ & 65414 & + & + & + & + \\
\hline 2 & TransATPKS & Macrolactin & BGC0000181_c1 (100\%) & $1440778-1526670$ & 85893 & + & + & - & - \\
\hline 3 & TransATPKS-NRPS & Bacillaene & BGC0001089_c1 (100\%) & $1756070-1858741$ & 102672 & + & + & + & + \\
\hline 4 & NRPS & Bacillomycin D & BGC0001090 (66\%) & $1936517-1981185$ & 44669 & + & + & - & - \\
\hline 5 & TransATPKS-NRPS & Fengycin & BGC0001095_c1 (100\%) & $1989975-2039517$ & 49543 & + & + & + & + \\
\hline 6 & TransATPKS & Difficidin & BGC0000176_c1 (100\%) & $2460543-2560999$ & 100457 & + & + & - & - \\
\hline 7 & Bacteriocin-NRPS & Bacillibactin & BGC0001185_c1 (100\%) & $3272524-3339313$ & 66790 & + & + & + & + \\
\hline 8 & NRPS & Bacilysin & BGC0000309_c1 (100\%) & $3895380-3953631$ & 58252 & + & + & + & + \\
\hline 9 & TransATPKS-NRPS & Rhizocticin & BGC0000926_c (22\%) & $191893-269628$ & 77736 & - & - & - & - \\
\hline 10 & Lantipeptide & Subtilin-like / Ericin & BGC0000511_c1 (100\%) & $3485394-3500516$ & 15123 & - & - & - & - \\
\hline 11 & NRPS & - & - & $3625021-3693450$ & 68430 & - & - & - & - \\
\hline 12 & OtherKS & - & - & $986643-1027887$ & 41245 & + & + & - & - \\
\hline 13 & T3PKS & - & - & $2166999-2208099$ & 41101 & + & + & + & + \\
\hline 14 & Terpene & - & - & $1110586-1131326$ & 20741 & + & + & + & + \\
\hline 15 & Terpene & - & - & $2080722-2102605$ & 21884 & + & + & + & + \\
\hline
\end{tabular}

(Footnote: Prediction of secondary metabolites clusters of Bacillus strains were performed through the antiSMASH web server (Medema et al. 2011; Blin et al. 2013; Weber et al. 2015).) 
Table 3: Comparative analysis of genes involved in biofilm formation in B. velezensis QST713 with $B$. velezensis $\left.\mathrm{FZB} 42 .{ }^{*}\right)$ represents the longest nucleotide sequence taken as a basis for BLAST comparison.

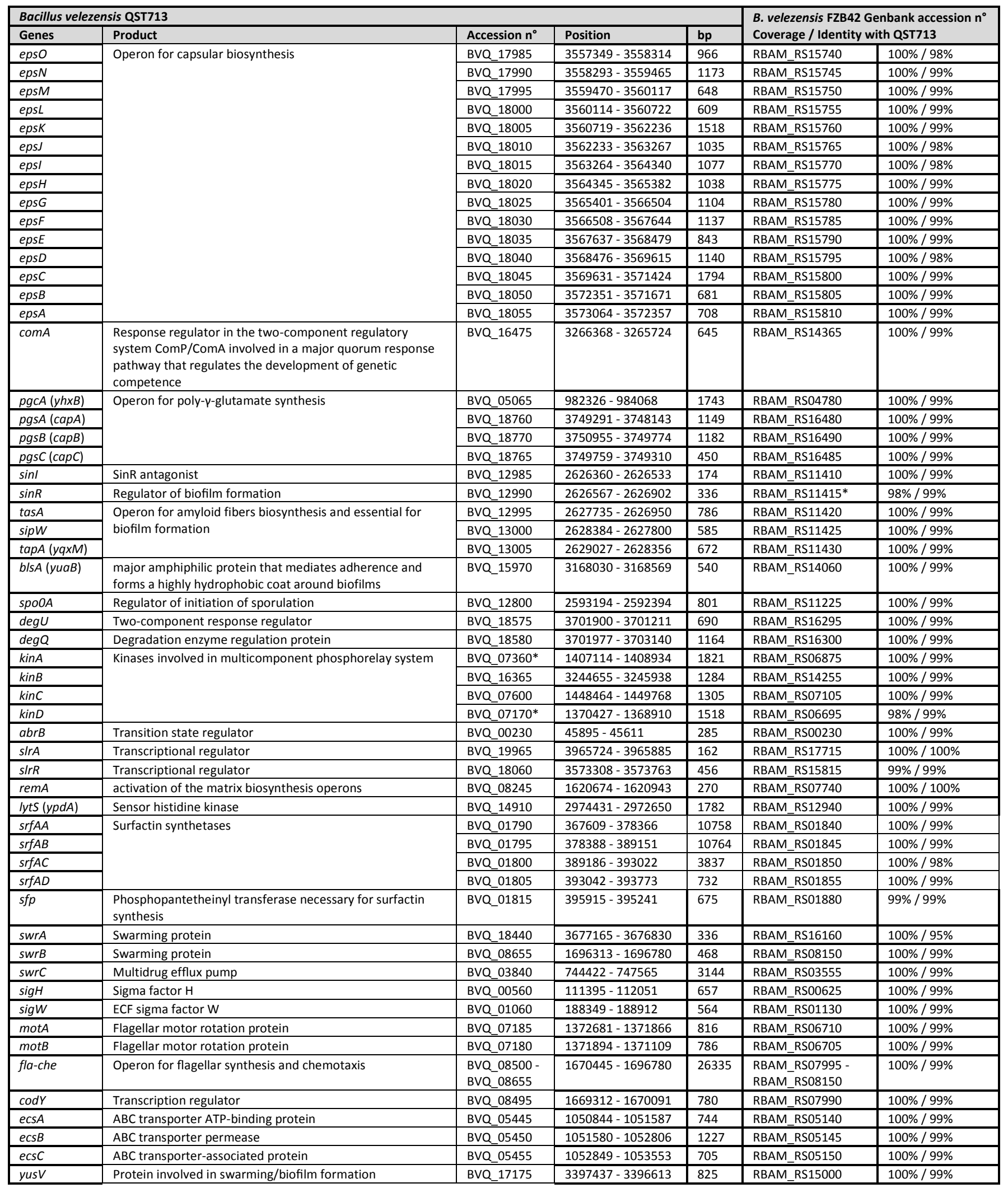


Fig. 1

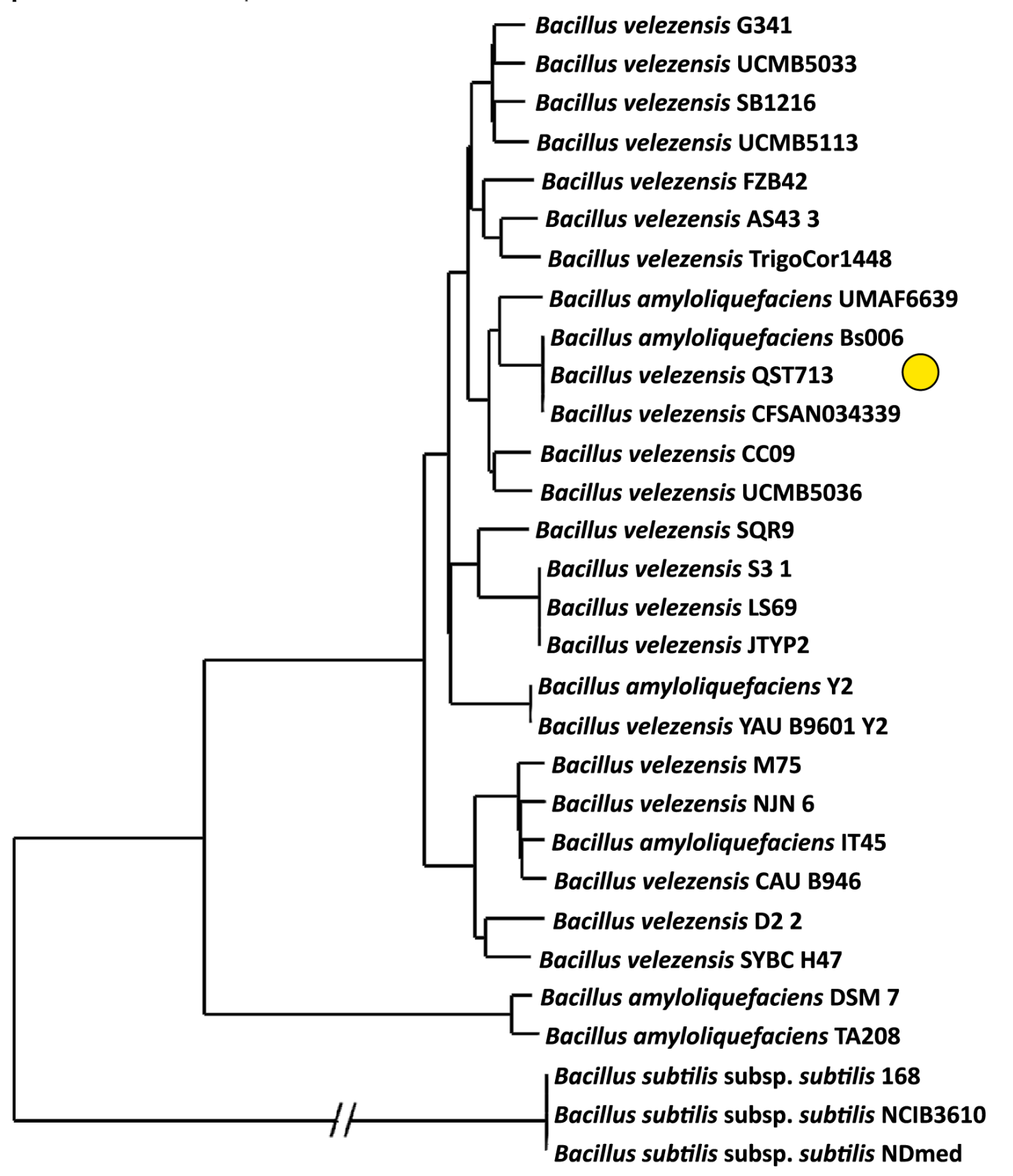

B. velezensis 
Fig. 2

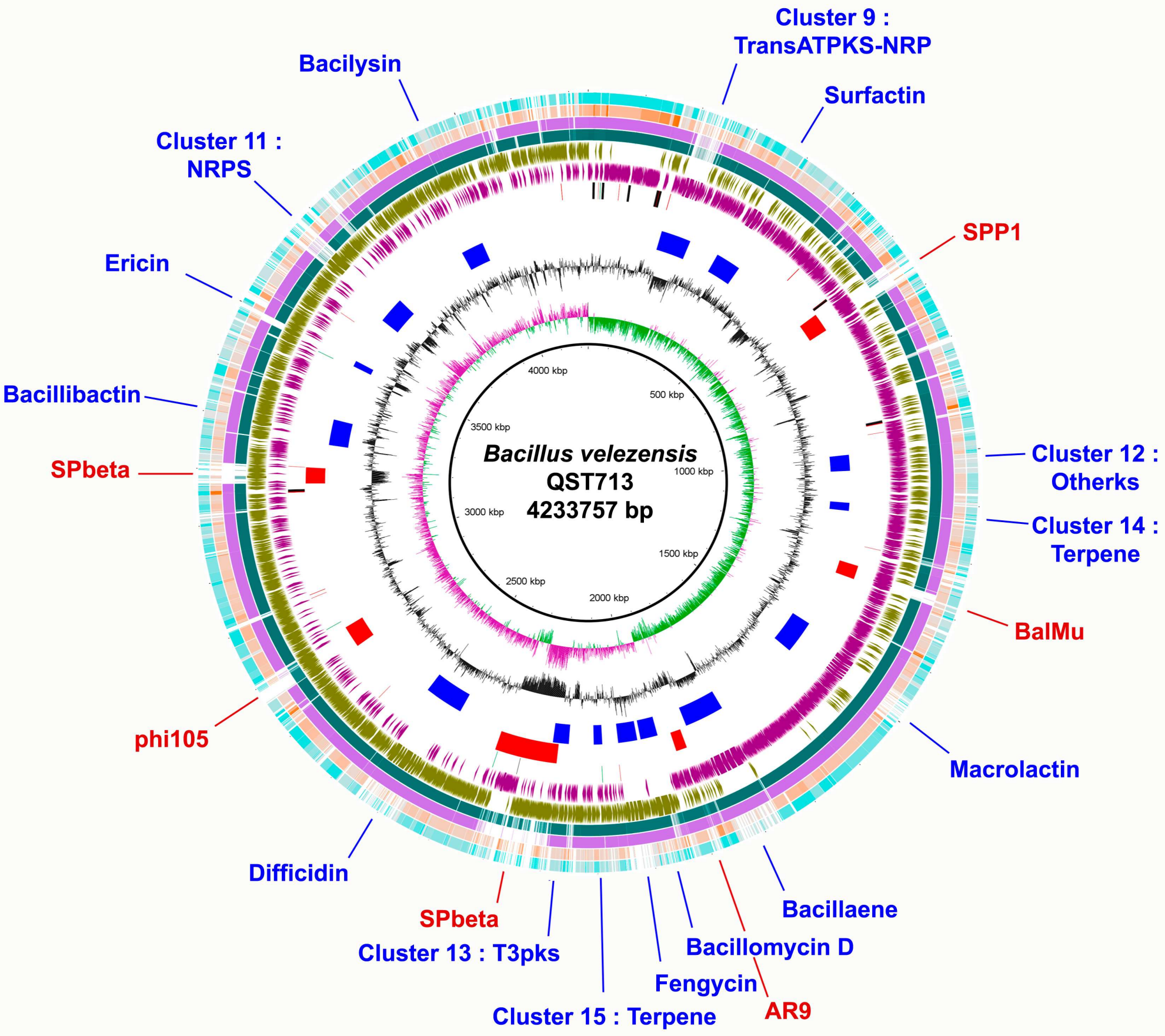


Fig. 3

Surfactin

Macrolactin

Bacillaene

Bacillomycin D

Fengycin

Difficidin

Bacillibactin

Cluster 9 :

TransATPKS-NRPS

Ericin/subtilin-like

Cluster 11: NRPS

Bacilysin
QST713

FZB42

srfAA

srfAB

srfAC srfADtpaat

QST713

FZB42

unknown $m \ln A$

$m \ln B$

$m \ln C \quad m \ln D$

$m \ln E$

$m \ln F$

$m \ln G$

$m I n H I$ pdhA

QST713

FZB42

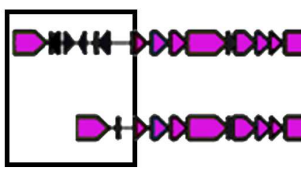

mutL baeBCDEbaeGHI baeJ unknown acpK

bael

baeM

baeN

baeRS nucB

QST713

FZB42
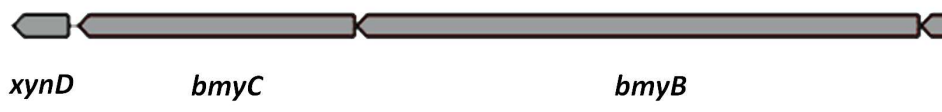

bmyB

bmyA

bmyD yxjF

QST713

FZB42

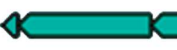

$\longrightarrow$
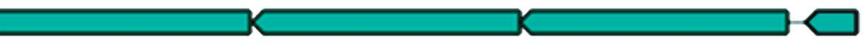

QST713

FZB42
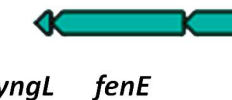

$$
\text { fenD }
$$

fenc

fenB

fenA

$\operatorname{dacC}$

QST713

FZB42

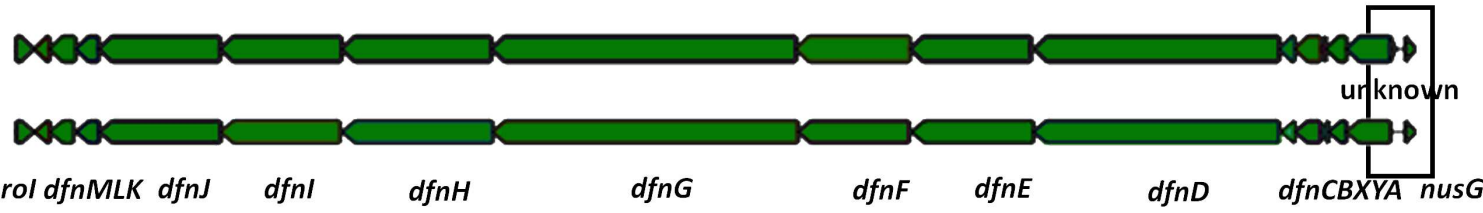

QST713

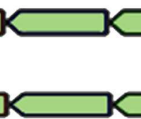

$y b d z$

$d h b F$

dhbB dhbE

dhbc dhbA yuil

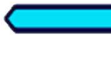

$$
\text { ywfG }
$$

bacE

bacD

bacc

bacB

bacA

ywfA

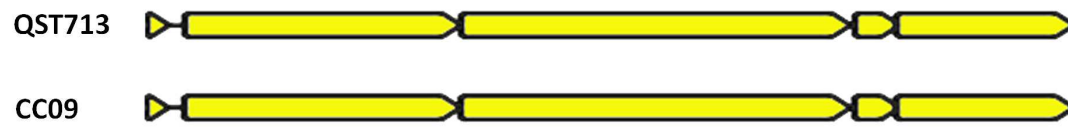

tnrpsA tnrpsB

tnrpsC

tnrpsDE

tnrpsFG

tnrpsH

QST713

A13

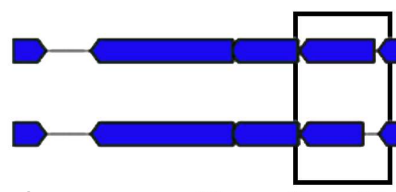

unknown

erik

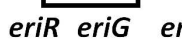

eriE erif eril eriSb eriSa eric

unknown

eriT

eriB
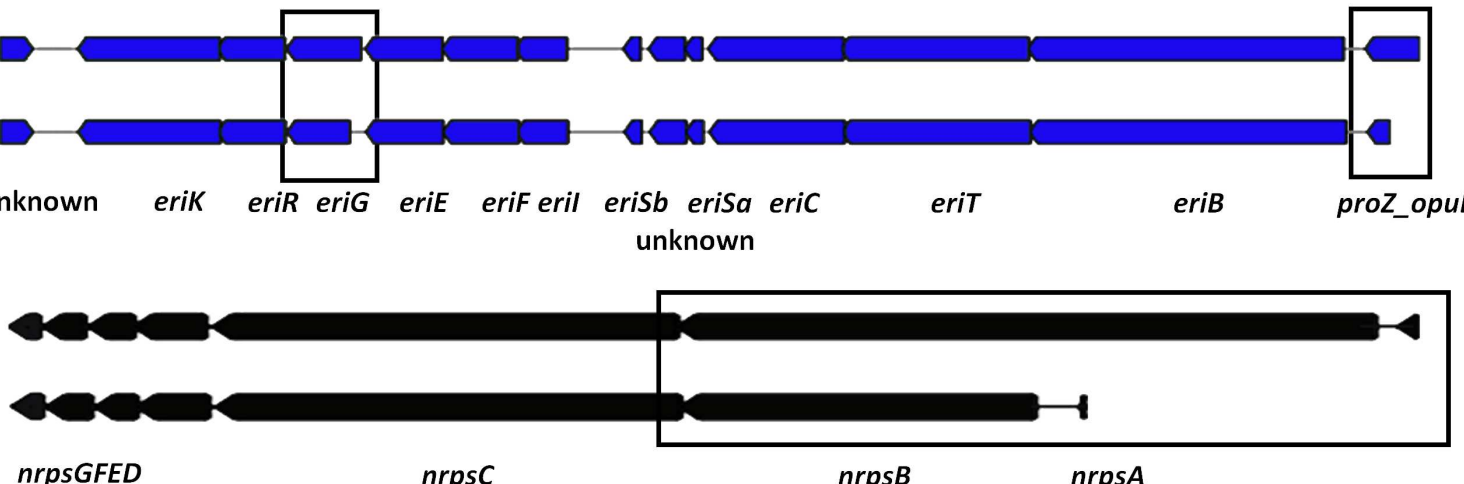
Fig. 4

swarming colonies pellicles

submerged biofilms

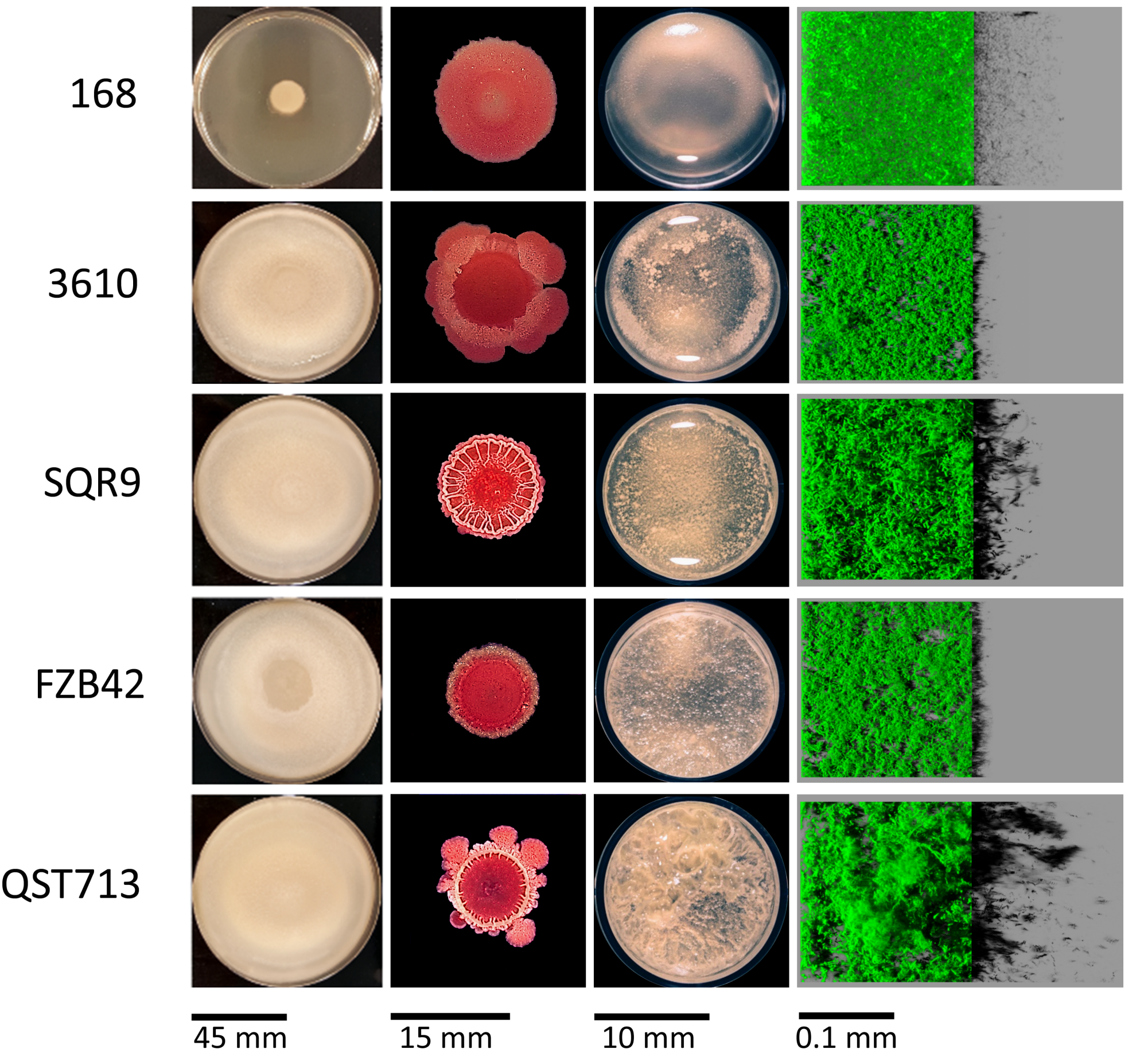


Fig. 5

A

B
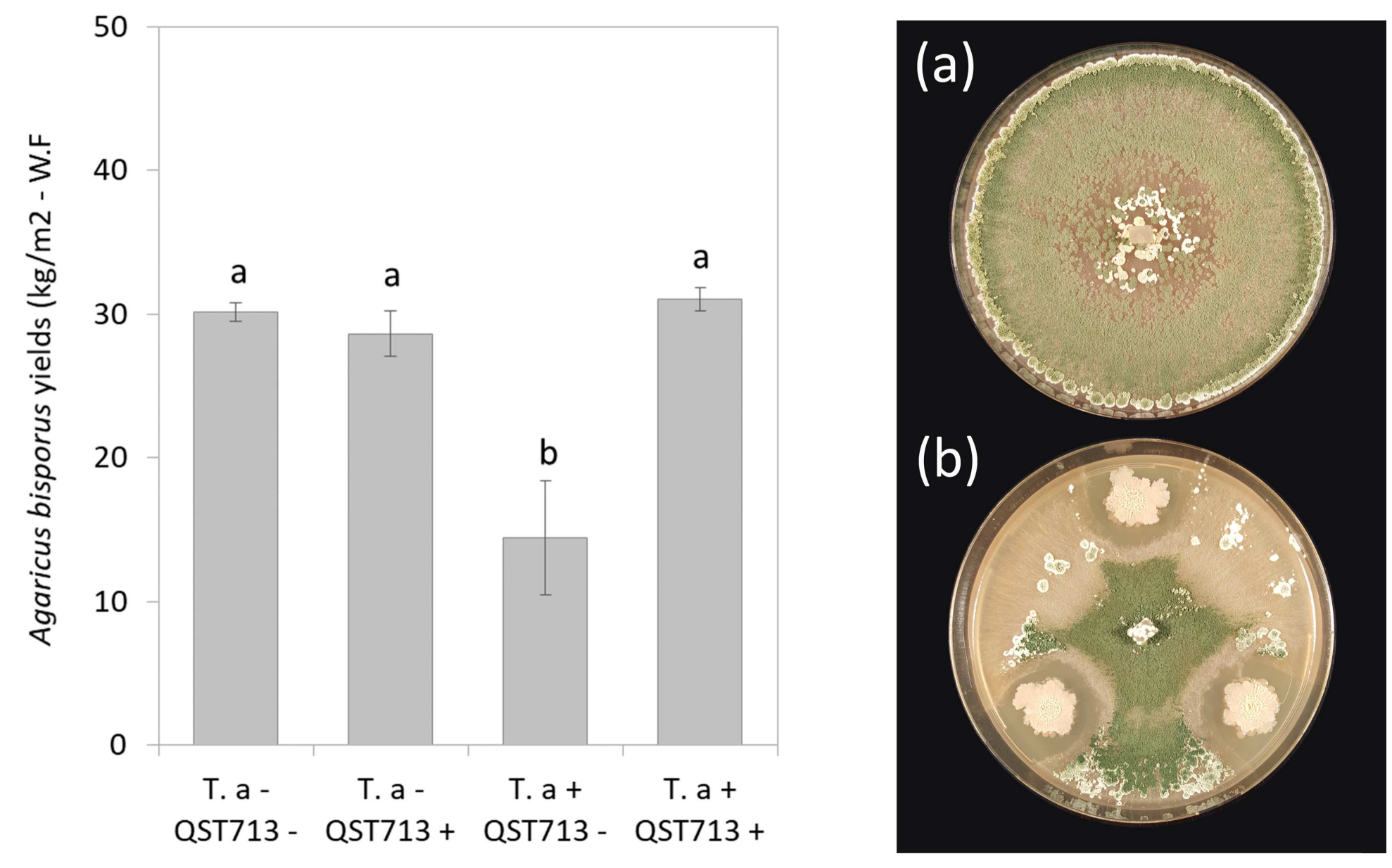


\section{Abstract}

2 Bacillus subtilis QST713 is extensively used as a biological control agent in agricultural fields

3 including in the button mushroom culture, Agaricus bisporus. This last use exploits its inhibitory

4 activity against microbial pathogens such as Trichoderma aggressivum f. europaeum, the main

5 button mushroom green mould competitor. Here, we report the complete genome sequence of the

6 QST713 biocontrol strain with a genome size of $4233757 \mathrm{bp}, 4263$ predicted genes and an

7 average GC content of $45.9 \%$. Based on phylogenomic analyses, the QST713 strain is finally

8 designated as Bacillus velezensis. Genomic analyses revealed two clusters encoding potential

9 new antimicrobials with NRPS and TransATPKS synthetase. B. velezensis QST713 genome also

10 harbours several genes previously described as being involved in surface colonization and

11 biofilm formation. This strain shows a strong ability to form in vitro spatially organized biofilm

12 and to antagonize T. aggressivum. The availability of this genome sequence could bring new

13 elements to understand the interactions with micro or/and macroorganisms in crops.

14 Keywords : Bacillus velezensis, Biofilm, Genome, Biocontrol, Secondary metabolites. 
Click here to download Supplementary File: Table S1 Pandin.docx

Table S1

.
lick here to download Supplementary File: Table S1 Pandin.docx (a) (1) (1) (1) (1) (1) (1)

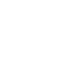

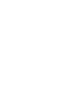

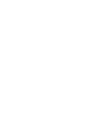
(n) 列 -

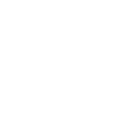

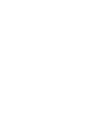

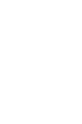

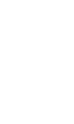

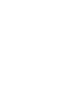
.

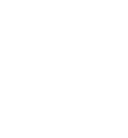

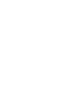

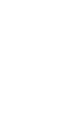

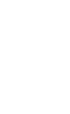
.

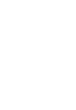
.

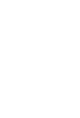

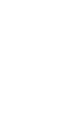

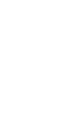

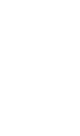

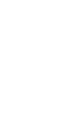

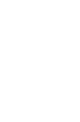

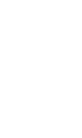

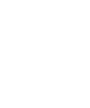

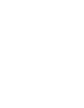

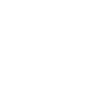

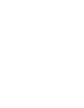

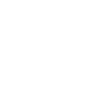

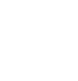

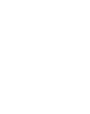


Table S2
Click here to download Supplementary File: Table S2 Pandin.docx

Table S2
Click here to download Supplementary File: Table S2 Pandin.docx

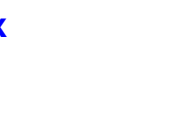


Click here to download Supplementary File: Fig. S1 Pandin.eps

Click here to download Supplementary File: Fig. S1 Pandin.eps

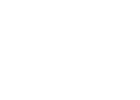

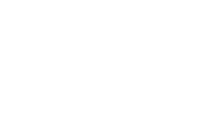


Table S1: Prophage regions of Bacillus velezensis QST713 genome.

\begin{tabular}{|c|c|c|c|c|c|c|c|c|c|}
\hline Region & $\begin{array}{l}\text { Region } \\
\text { length }\end{array}$ & Completeness & $\begin{array}{l}\text { Number } \\
\text { of CDS }\end{array}$ & $\begin{array}{l}\text { Phage Hit } \\
\text { protein }\end{array}$ & $\begin{array}{l}\text { Hypothetical } \\
\text { protein }\end{array}$ & Specific Keyword & Region_position & Possible phage & $\begin{array}{l}\mathrm{G}+\mathrm{C} \\
\text { percentage }\end{array}$ \\
\hline 1 & $44.8 \mathrm{~Kb}$ & questionable & 71 & 45 & 26 & $\begin{array}{l}\text { integrase, terminase, } \\
\text { portal, capsid, tail }\end{array}$ & $630065-674933$ & PHAGE_Bacill_SPP1_NC_004166 & $43.88 \%$ \\
\hline 2 & $32.8 \mathrm{~Kb}$ & questionable & 45 & 32 & 13 & $\begin{array}{l}\text { terminase, head, capsid, } \\
\text { tail, portal, plate }\end{array}$ & $1260401-1293209$ & PHAGE_Bacill_BalMu_1_NC_030945 & $46.83 \%$ \\
\hline 3 & $26.4 \mathrm{~Kb}$ & incomplete & 11 & 8 & 3 & tail, recombinase & $1876725-1903221$ & PHAGE_Bacill_AR9_NC_031039 & $41.48 \%$ \\
\hline 4 & $150.2 \mathrm{~Kb}$ & incomplete & 180 & 112 & 68 & virion, tail, recombinase & $2192669-2342879$ & PHAGE_Bacill_SPbeta_NC_001884 & $36.62 \%$ \\
\hline 5 & $52.5 \mathrm{~Kb}$ & questionable & 53 & 41 & 12 & integrase, portal & $2760236-2812785$ & PHAGE_Bacill_phi105_NC_004167 & $43.51 \%$ \\
\hline 6 & $38.5 \mathrm{~Kb}$ & questionable & 30 & 22 & 8 & tail, head, capsid, portal & $3173273-3211799$ & PHAGE_Bacill_SPbeta_NC_001884 & $36.03 \%$ \\
\hline
\end{tabular}

(Footnote: Prophage regions were identified using PHASTER web server (Zhou et al. 2011; Arndt et al. 2016).) 
Table S2: Comparative analysis of gene clusters encoding secondary metabolites in B. velezensis QST713 with Bacillus strains. (*) represents the longest nucleotide sequence taken as a basis for BLAST comparison.

\begin{tabular}{|c|c|c|c|c|c|c|c|c|}
\hline Bacillus v & ezensis QST713 & & & & & & \multirow{2}{*}{\multicolumn{2}{|c|}{$\begin{array}{l}\text { Genbank accession number } \\
\text { Blast Coverage / Identity nt sequence } \\
\text { QST713 with Bacillus species } \\
\text { B. velezensis FZB42 }\end{array}$}} \\
\hline $\begin{array}{l}\text { Cluster } \\
\text { number }\end{array}$ & Metabolites & Synthetase & Main genes & Accession & Position & bp & & \\
\hline \multirow[t]{6}{*}{1} & Surfactin & NRPS & $x y 02$ & BVQ_01785 & $367201-367425$ & 225 & RBAM_RS01835 & $100 \% / 99 \%$ \\
\hline & & & srfAA & BVQ_01790 & $367609-378366$ & 10758 & RBAM_RS01840 & $100 \% / 99 \%$ \\
\hline & & & $s r f A B$ & BVQ_01795 & $378388-389151$ & 10764 & RBAM_RS01845 & $100 \% / 99 \%$ \\
\hline & & & srfAC & BVQ_01800 & $389186-393022$ & 3837 & RBAM_RS01850 & $100 \% / 98 \%$ \\
\hline & & & $s r f A D$ & BVQ_01805 & $393042-393773$ & 732 & RBAM_RS01855 & $100 \% / 99 \%$ \\
\hline & & & tpaat & BVQ_01810 & $393895-395205$ & 1311 & RBAM_RS01860 & $100 \% / 99 \%$ \\
\hline \multirow[t]{11}{*}{2} & Macrolactin & TransATPKS & unknown & BVQ_07650 & $1458250-1458449$ & 200 & RBAM_RS07155 & $98 \% / 99 \%$ \\
\hline & & & $m \ln A$ & BVQ_07655 & $1458450-1460756$ & 2307 & RBAM_RS07160 & $100 \% / 99 \%$ \\
\hline & & & $m \ln B$ & BVQ_07660 & $1460778-1473032$ & 12255 & RBAM_RS07165* & $100 \%$ / $99 \%$ \\
\hline & & & $m \ln C$ & BVQ_07665 & $1473032-1477804$ & 4773 & RBAM_RS07170 & $100 \% / 98 \%$ \\
\hline & & & $m \ln D$ & BVQ_07670 & 1477851 - 1486559 & 8709 & RBAM_RS07175 & $100 \% / 99 \%$ \\
\hline & & & $m \ln E$ & BVQ_07675 & $1486552-1493556$ & 7005 & RBAM_RS07180 & $100 \% / 99 \%$ \\
\hline & & & $m \ln F$ & BVQ_07680 & $1493580-1499291$ & 5712 & RBAM_RS07185 & $100 \% / 99 \%$ \\
\hline & & & $m \ln G$ & BVQ_07685 & $1499291-1506670$ & 7380 & RBAM_RS07190 & $100 \% / 99 \%$ \\
\hline & & & $m \operatorname{lnH}$ & BVQ_07690 & $1506721-1510569$ & 3849 & RBAM_RS07195* & $100 \% / 98 \%$ \\
\hline & & & $m / n l$ & BVQ_07695 & $1510602-1511693$ & 1092 & RBAM_RS07200 & $100 \% / 99 \%$ \\
\hline & & & $p d h A$ & BVQ_07700 & $1512163-1513278$ & 1116 & RBAM_RS07205 & $100 \% / 99 \%$ \\
\hline \multirow[t]{23}{*}{3} & Bacillaene & TransATPKS-NRPS & mutL & BVQ_08940* & $1760813-1762687$ & 1875 & RBAM_RS08435 & $99 \% / 99 \%$ \\
\hline & & & unknown & BVQ_08945 & $1762739-1762888$ & 150 & - & - \\
\hline & & & unknown & BVQ_08950 & $1762848-1763354$ & 507 & - & - \\
\hline & & & unknown & BVQ_08955 & $1763792-1764094$ & 303 & - & - \\
\hline & & & unknown & BVQ_08960 & $1764573-1764782$ & 210 & - & - \\
\hline & & & unknown & BVQ_08965* & $1765319-1765528$ & 210 & RBAM_RS08440 & $99 \%-97 \%$ \\
\hline & & & unknown & BVQ_08970 & $1765615-1766136$ & 522 & - & - \\
\hline & & & unknown & BVQ_08975 & $1767460-1767675$ & 216 & - & - \\
\hline & & & baeB & BVQ_08980 & $1767659-1768336$ & 678 & RBAM_RS08445 & $100 \% / 99 \%$ \\
\hline & & & baec & BVQ_08985 & $1768651-1769520$ & 870 & RBAM_RS08450 & $100 \% / 99 \%$ \\
\hline & & & baeD & BVQ_08990 & $1769657-1770631$ & 975 & RBAM_RS08455 & $100 \% / 99 \%$ \\
\hline & & & baeE & BVQ_08995 & $1770633-1772873$ & 2241 & RBAM_RS08460 & $100 \% / 99 \%$ \\
\hline & & & $a c p K$ & BVQ_09000 & $1772939-1773187$ & 249 & RBAM_RS08465 & $100 \% / 99 \%$ \\
\hline & & & baeG & BVQ_09005 & $1773239-1774501$ & 1263 & RBAM_RS08470 & $100 \% / 98 \%$ \\
\hline & & & baeH & BVQ_09010 & $1774498-1775271$ & 774 & RBAM_RS08475 & $100 \% / 99 \%$ \\
\hline & & & bael & BVQ_09015 & $1775281-1776030$ & 750 & RBAM_RS08480 & $100 \% / 100 \%$ \\
\hline & & & baeJ & BVQ_09020* & 1776070 - 1791021 & 14952 & RBAM_RS08485 & $100 \% / 98 \%$ \\
\hline & & & bael & BVQ_09025 & $1791023-1804429$ & 13407 & RBAM_RS08490* & $100 \% / 98 \%$ \\
\hline & & & baeM & BVQ_09030 & $1804447-1814982$ & 10536 & RBAM_RS08495 & $100 \% / 98 \%$ \\
\hline & & & baeN & BVQ_09035 & $1814972-1831270$ & 16299 & RBAM_RS08500* & $100 \% / 98 \%$ \\
\hline & & & baeR & BVQ_09040* & $1831284-1838741$ & 7458 & RBAM_RS08505 & $100 \% / 98 \%$ \\
\hline & & & baes & BVQ_09045 & $1840089-1838878$ & 1212 & RBAM_RS08510 & $100 \% / 99 \%$ \\
\hline & & & $n u c B$ & BVQ_09050 & $1840378-1840812$ & 435 & RBAM_RS08515 & $100 \% / 99 \%$ \\
\hline \multirow[t]{6}{*}{4} & Bacillomycin D & NRPS & xynD & BVQ_09605 & $1937867-1939405$ & 1539 & RBAM_RS09060 & $99 \% / 94 \%$ \\
\hline & & & bmyC & BVQ_09610 & $1939730-1947586$ & 7857 & RBAM_RS09065* & $100 \% / 68 \%$ \\
\hline & & & $b m y B$ & BVQ_09615 & $1947675-1963763$ & 16089 & RBAM_RS09070* & $100 \% / 82 \%$ \\
\hline & & & bmyA & BVQ_09620 & $1963808-1975756$ & 11949 & RBAM_RS09075 & $100 \%$ / $99 \%$ \\
\hline & & & $b m y D$ & BVQ_09625 & $1975776-1976978$ & 1203 & RBAM_RS09080 & $100 \% / 97 \%$ \\
\hline & & & $y x j F$ & BVQ_09635 & $1977536-1978321$ & 786 & RBAM_RS09085 & $100 \% / 98 \%$ \\
\hline \multirow[t]{7}{*}{5} & Fengycin & TransATPKS-NRPS & yngL & BVQ_09740 & 1999440 - 1999820 & 381 & RBAM_RS09190 & $100 \% / 99 \%$ \\
\hline & & & fenE & BVQ_09745 & $2003696-1999893$ & 3804 & RBAM_RS09195 & $100 \% / 98 \%$ \\
\hline & & & fenD & BVQ_09750 & $2014490-2003715$ & 10776 & RBAM_RS09200 & $100 \% / 99 \%$ \\
\hline & & & fenC & BVQ_09755 & $2022165-2014516$ & 7650 & RBAM_RS09205 & $100 \% / 98 \%$ \\
\hline & & & fenB & BVQ_09760 & $2029878-2022181$ & 7698 & RBAM_RS09210 & $100 \% / 98 \%$ \\
\hline & & & fenA & BVQ_09765 & $2037562-2029904$ & 7659 & RBAM_RS09215 & $100 \% / 98 \%$ \\
\hline & & & dacC & BVQ_09775 & $2039517-2038042$ & 1476 & RBAM_RS09220 & $100 \% / 98 \%$ \\
\hline \multirow[t]{8}{*}{6} & Difficidin & TransATPKS & prol & BVQ_12475 & $2476320-2477159$ & 840 & RBAM_RS10905 & $100 \% / 99 \%$ \\
\hline & & & $d f n M$ & BVQ_12480 & $2477942-2477196$ & 747 & RBAM_RS10910 & $100 \% / 98 \%$ \\
\hline & & & $d f n L$ & BVQ_12485 & $2479249-2478002$ & 1248 & RBAM_RS10915 & $99 \% / 99 \%$ \\
\hline & & & $d f n K$ & BVQ_12490 & $2480461-2479307$ & 1155 & RBAM_RS10920 & $100 \% / 99 \%$ \\
\hline & & & $d f n J$ & BVQ_12495 & $2486758-2480543$ & 6216 & RBAM_RS10925 & $100 \%$ / $99 \%$ \\
\hline & & & $d f n l$ & BVQ_12500 & $2492907-2486755$ & 6153 & RBAM_RS10930 & $100 \% / 99 \%$ \\
\hline & & & $d f n H$ & BVQ_12505 & $2500648-2492930$ & 7719 & RBAM_RS10935 & $100 \% / 98 \%$ \\
\hline & & & $d f n G$ & BVQ_12510 & $2516267-2500653$ & 15615 & RBAM_RS10940 & $100 \% / 98 \%$ \\
\hline
\end{tabular}




\begin{tabular}{|c|c|c|c|c|c|c|c|c|}
\hline & & & $d f n F$ & BVQ_12515 & $2522045-2516319$ & 5727 & RBAM_RS10945 & $100 \% / 98 \%$ \\
\hline & & & $d f n E$ & BVQ_12520 & $2528381-2522085$ & 6297 & RBAM_RS10950 & $100 \% / 98 \%$ \\
\hline & & & $d f n D$ & BVQ_12525* & $2540999-2528400$ & 12600 & RBAM_RS10955 & $100 \% / 98 \%$ \\
\hline & & & $d f n C$ & BVQ_12530 & $2541776-2541039$ & 738 & RBAM_RS10960 & $100 \% / 99 \%$ \\
\hline & & & $d f n B$ & BVQ_12535 & $2543155-2541791$ & 1365 & RBAM_RS10965 & $100 \% / 99 \%$ \\
\hline & & & $d f n X$ & BVQ_12540 & $2543424-2543152$ & 273 & RBAM_RS10970 & $100 \% / 99 \%$ \\
\hline & & & $d f n Y$ & BVQ_12545 & $2544429-2543449$ & 981 & RBAM_RS10975 & $100 \% / 99 \%$ \\
\hline & & & $d f n A$ & BVQ_12550 & $2546728-2544470$ & 2259 & RBAM_RS10980 & $100 \% / 99 \%$ \\
\hline & & & unknown & BVQ_12555 & $2546772-2546957$ & 186 & - & - \\
\hline & & & nusG & BVQ_12560 & $2547462-2547992$ & 531 & RBAM_RS10985 & $100 \% / 99 \%$ \\
\hline 7 & Bacillibactin & NRPS & $y b d z$ & BVQ_16605 & $3292505-3292290$ & 216 & RBAM_RS14485 & $100 \% / 98 \%$ \\
\hline & & & $d h b F$ & BVQ_16610 & 3299651 - 3292524 & 7128 & RBAM_RS14490 & $100 \%$ / 99\% \\
\hline & & & $d h b B$ & BVQ_16615 & $3300592-3299666$ & 927 & RBAM_RS14495 & $100 \% / 98 \%$ \\
\hline & & & $d h b E$ & BVQ_16620 & $3302235-3300610$ & 1626 & RBAM_RS14500 & $100 \% / 99 \%$ \\
\hline & & & $d h b c$ & BVQ_16625 & $3303450-3302254$ & 1197 & RBAM_RS14505 & $100 \% / 99 \%$ \\
\hline & & & $d h b A$ & BVQ_16630 & $3304259-3303474$ & 786 & RBAM_RS14510 & $100 \% / 99 \%$ \\
\hline & & & yuil & BVQ_16635 & $3305264-3304395$ & 870 & RBAM_RS14515 & $100 \% / 99 \%$ \\
\hline 8 & Bacilysin & NRPS & $y w f g$ & BVQ_19710 & $3914189-3912990$ & 1200 & RBAM_RS17415 & $100 \% / 99 \%$ \\
\hline & & & bacE & BVQ_19715 & $3914202-3915383$ & 1182 & RBAM_RS17420 & $100 \%$ / 99\% \\
\hline & & & $b a c D$ & BVQ_19720 & $3915380-3916798$ & 1419 & RBAM_RS17425 & $100 \% / 99 \%$ \\
\hline & & & bacC & BVQ_19725 & $3917577-3916816$ & 762 & RBAM_RS17430 & $100 \% / 99 \%$ \\
\hline & & & $b a c B$ & BVQ_19730 & $3918284-3917574$ & 711 & RBAM_RS17435 & $100 \% / 100 \%$ \\
\hline & & & bacA & BVQ_19735 & $3918888-3918274$ & 615 & RBAM_RS17440 & $100 \% / 99 \%$ \\
\hline & & & $y w f A$ & BVQ_19740 & $3920287-3919049$ & 1239 & RBAM_RS17445 & $100 \% / 99 \%$ \\
\hline $\begin{array}{l}\text { Cluster } \\
\text { number }\end{array}$ & Metabolites & Synthetase & genes & Accession & Position & Bp & \multicolumn{2}{|l|}{ B. velezensis $\mathrm{CCO9}$} \\
\hline 9 & Unknown & TransATPKS-NRPS & tnrpsA & BVQ_01170 & $210823-211518$ & 696 & A1D33_RS08065 & $100 \% / 99 \%$ \\
\hline & & & tnrpsB & BVQ_01175 & $211893-219515$ & 7623 & A1D33_RS08060 & $100 \%$ / 99\% \\
\hline & & & tnrpsC & BVQ_01180 & $219475-230232$ & 10758 & A1D33_RS08055 & $100 \% / 99 \%$ \\
\hline & & & tnrpsD & BVQ_01185 & $230315-231568$ & 1254 & A1D33_RS08050 & $100 \% / 99 \%$ \\
\hline & & & tnrpsE & BVQ_01190 & $231492-236384$ & 4893 & A1D33_RS08045 & $100 \% / 99 \%$ \\
\hline & & & tnrpsF & BVQ_01195 & $236569-241359$ & 4791 & A1D33_RS08040 & $100 \% / 99 \%$ \\
\hline & & & tnrpsG & BVQ_01200 & $241381-242904$ & 1524 & A1D33_RS08035 & $100 \% / 99 \%$ \\
\hline & & & tnrpsH & BVQ_01205* & $243002-249628$ & 6627 & A1D33_RS08030 & $100 \% / 99 \%$ \\
\hline $\begin{array}{l}\text { Cluster } \\
\text { number }\end{array}$ & Metabolites & Synthetase & genes & Accession & Position & bp & \multicolumn{2}{|c|}{ Bacillus subtilis strain A13 } \\
\hline \multirow[t]{14}{*}{10} & Subtilin-like/Ericin & Lantipeptide & unknown & BVQ_17650 & $3486343-3486663$ & 321 & AAL15576 & $100 \% / 100 \%$ \\
\hline & & & erik & BVQ_17655 & $3488531-3487212$ & 1374 & AAL15574* & $98 \% / 100 \%$ \\
\hline & & & eriR & BVQ_17660 & $3489238-3488576$ & 663 & AAL15573 & $100 \% / 100 \%$ \\
\hline & & & eriG & BVQ_17665* & $3490026-3489256$ & 771 & AAL15575 & $79 \% / 100 \%$ \\
\hline & & & eriE & BVQ_17670 & $3490783-3490028$ & 756 & AAL15572 & $100 \% / 100 \%$ \\
\hline & & & eriF & BVQ_17675 & $3491496-3490780$ & 717 & AAL15571* & $96 \% / 100 \%$ \\
\hline & & & eril & BVQ_17680 & $3492004-3491498$ & 507 & AAL15570 & $100 \% / 100 \%$ \\
\hline & & & $e r i S b$ & BVQ_17685 & $3492726-3492556$ & 171 & AAL15569 & $100 \% / 100 \%$ \\
\hline & & & unknown & BVQ_17690 & $3492828-3493160$ & 333 & AAL15568* & $93 \% / 100 \%$ \\
\hline & & & eriSa & BVQ_17695 & $3493315-3493154$ & 162 & AAL15567* & $94 \% / 100 \%$ \\
\hline & & & eriC & BVQ_17700 & $3494713-3493388$ & 1326 & AAL15566 & $100 \% / 100 \%$ \\
\hline & & & eriT & BVQ_17705 & $3496530-3494686$ & 1845 & AAL15565 & $100 \% / 100 \%$ \\
\hline & & & eriB & BVQ_17710 & $3499613-3496521$ & 3093 & AAL15564 & $100 \% / 100 \%$ \\
\hline & & & proZ/opuBD & BVQ_17715* & $3500498-3499827$ & 672 & AAL15578 & $33 \% / 99 \%$ \\
\hline $\begin{array}{l}\text { Cluster } \\
\text { number }\end{array}$ & Metabolites & Synthetase & genes & Accession & Position & bp & \multicolumn{2}{|l|}{ B. velezensis CCO9 } \\
\hline \multirow[t]{7}{*}{11} & Unknown & NRPS & $n r p s G$ & BVQ_18400 & $3640781-3640056$ & 726 & A1D33_RS12065* & $93 \% / 99 \%$ \\
\hline & & & $n r p s F$ & BVQ_18405 & $3641902-3640832$ & 1071 & A1D33_RS12060 & $100 \% / 99 \%$ \\
\hline & & & nrpsE & BVQ_18410 & $3643049-3641988$ & 1062 & A1D33_RS12055 & $100 \% / 99 \%$ \\
\hline & & & $n r p s D$ & BVQ_18415 & $3644824-3643082$ & 1743 & A1D33_RS12050 & $100 \% / 99 \%$ \\
\hline & & & nrpsC & BVQ_18420 & $3656339-3645021$ & 11319 & A1D33_RS12045 & $100 \% / 99 \%$ \\
\hline & & & $n r p s B$ & BVQ_18425* & $3673450-3656351$ & 17100 & A1D33_RS12040 & $63 \% / 98 \%$ \\
\hline & & & $n r p s A$ & BVQ_18430* & $3674486-3673957$ & 530 & A1D33_RS12035 & $86 \% / 99 \%$ \\
\hline $\begin{array}{l}\text { Cluster } \\
\text { number }\end{array}$ & Metabolites & Synthetase & genes & Accession & Position & bp & \multicolumn{2}{|l|}{ B. velezensis FZB42 } \\
\hline 12 & - & OtherKS & - & $\begin{array}{l}\text { BVQ_05095 - } \\
\text { BVQ_05305 }\end{array}$ & $986643-1027887$ & 41245 & $\begin{array}{l}\text { RBAM_RS04810 - } \\
\text { RBAM_RS05005 }\end{array}$ & $100 \% / 99 \%$ \\
\hline 13 & - & T3PKS & - & $\begin{array}{l}\text { BVQ_10520 - } \\
\text { BVQ_10820 }\end{array}$ & $2166999-2208099$ & 41101 & $\begin{array}{l}\text { RBAM_RS09935 - } \\
\text { RBAM_RS08595 }\end{array}$ & $65 \% / 99 \%$ \\
\hline 14 & - & Terpene & - & $\begin{array}{l}\text { BVQ_05725 - } \\
\text { BVQ_05840 }\end{array}$ & $1110586-1131326$ & 20741 & $\begin{array}{l}\text { RBAM_RS05415 - } \\
\text { RBAM_RS05525 }\end{array}$ & $89 \% / 99 \%$ \\
\hline 15 & - & Terpene & - & $\begin{array}{l}\text { BVQ_09985 - } \\
\text { BVQ_10100 }\end{array}$ & $2080722-2102605$ & 21884 & RBAM_RS09450 & $92 \% / 99 \%$ \\
\hline
\end{tabular}




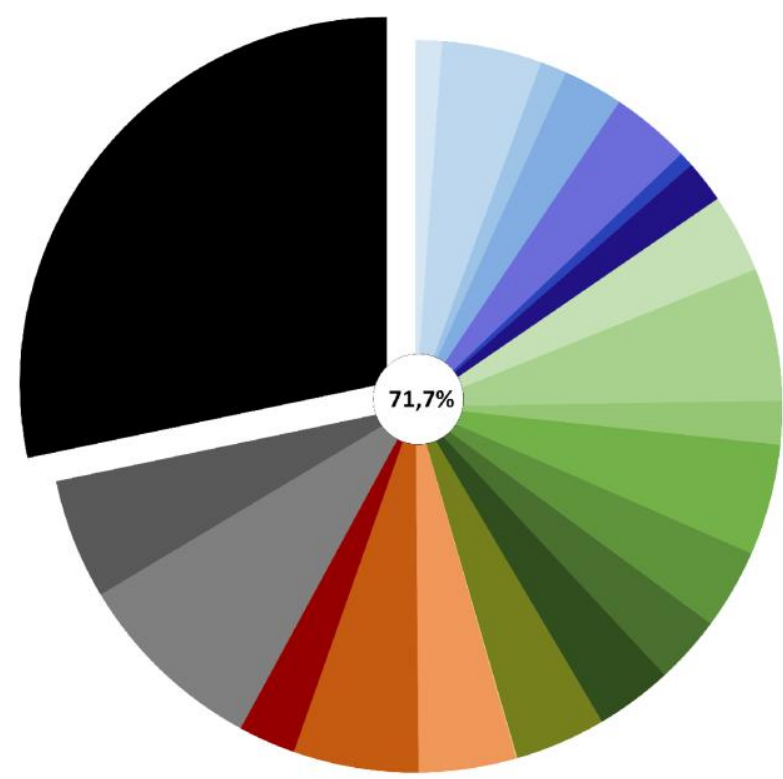

POORLY CHARACTERIZED

General function prediction only

Function unknown

Not in COGs

\section{CELLULAR PROCESSES \& SIGNALING}

Cell cycle control, cell division, chromosome partitioning

Cell wall/membrane/envelope biogenesis

Cell motility

Post-translational modification, protein turnover, chaperones

Signal transduction mechanisms

Intracellular trafficking, secretion, and vesicular transport

Defense mechanisms

\section{METABOLISM}

Energy production and conversion

Amino acid transport and metabolism

Nucleotide transport and metabolism

Carbohydrate transport and metabolism

Coenzyme transport and metabolism

Lipid transport and metabolism

Inorganic ion transport and metabolism

Secondary metabolites biosynthesis, transport and catabolism

\section{INFORMATION STORAGE \& PROCESSING}

RNA processing and modification

Chromatin structure and dynamics

Translation, ribosomal structure and biogenesis

Transcription

Replication, recombination and repair 